José Carlos Benatti Neto

Efeito das propriedades termofísicas da mistura refrigerante - nano-óleo no ciclo de refrigeração por compressão de vapor

PROJETO DE GRADUAÇÃO

DEPARTAMENTO DE ENGENHARIA

MECÂNICA

Programa de Graduação em

Engenharia Mecânica 
José Carlos Benatti Neto

Efeito das propriedades termofísicas da mistura refrigerante nano-óleo no ciclo de refrigeração por compressão de vapor

PROJETO DE GRADUAÇÃO

Projeto apresentado como requisito para obtenção de grau de Bacharel pelo Programa de Graduação em Engenharia Mecânica do Departamento de Engenharia Mecânica da PUC-Rio.

Orientador José Alberto dos Reis Parise

Coorientador

Paul Ortega Sotomayor

Rio de Janeiro, Julho de 2015 


$$
\begin{aligned}
& \text { Pontifícia Universidade } \text { Católica }_{\text {ata }} \\
& \text { DO RIO DE JANEIRO }
\end{aligned}
$$

\section{EFEITO DAS PROPRIEDADES \\ TERMOFÍSICAS DA MISTURA \\ REFRIGERANTE - NANO-ÓLEO NO CICLO \\ DE REFRIGERAÇÃO POR COMPRESSÃO DE \\ VAPOR}

Projeto de Graduação

Departamento de Engenharia Mecânica

Aluno: José Carlos Benatti Neto

Matrícula: 0921044

Orientador: José Alberto dos Reis Parise

Coorientador: Paul Ortega Sotomayor 


\section{Pontifícia Universidade Católica \\ DO RIO DE JANEIRO}

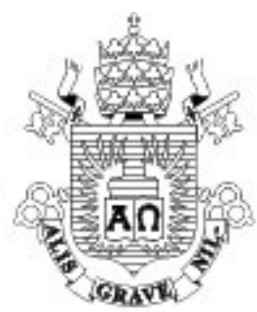

\section{EFFECT OF THERMOPHYSICAL MIXTURES PROPRERTIES REFRIGERANT - NANO-OIL IN THE VAPOR COMPRESSION REFRIGERATION CYCLE}

Projeto de Graduação

Departamento de Engenharia Mecânica Aluno: José Carlos Benatti Neto

Matrícula: 0921044

Orientador: José Alberto dos Reis Parise Coorientador: Paul Ortega Sotomayor

Rio de Janeiro, 02 de julho de 2015 


\section{AGRADECIMENTOS}

Primeiramente gostaria de agradecer ao professor José Alberto dos Reis Parise pela orientação do presente projeto.

Agradecer também ao pesquisador e co-orientador deste projeto, Paul Ortega Sotomayor, por ter me ajudado nas pesquisas e no desenvolvimento do projeto.

As palavras fogem nesse momento de agradecimento, mas gostaria de agradecer aos meus pais e irmã, que sempre estiveram comigo em todas as etapas da minha vida, me dando forças e apoiando, para nunca desistir e seguir em frente. Foram períodos difíceis, pois sei que engenharia não é um curso fácil, por isso obrigado aos três, pai, mãe e irmã por me me acalmarem nos momentos em que nada dava certo e motivarem a sempre levar orgulho para vocês. Amo demais vocês três. Muito obrigado.

Agradeço também a minha namorada Anna Camila Sousa e Silva, por me apoiar e me ajudar a passar por essa etapa da minha. Obrigado pelos conselhos e por me escutar nos momentos em que algo dava errado. Amo você.

Agradeço também ao meu amigo Matheus Cosenza que me acompanhou praticamente em toda a faculdade. Obrigado amigo por me escutar e me aconselhar em diversos momentos. "Tamo junto" amigo, e final do ano estarei presente na sua formatura.

Agradeço também aos meus amigos António Lucio, João Carlos Virgolino, Pedro Henrique Froner, Igor Girsas, Rodrigo Bianchi, Bruno Calasans e Matheus Lessa, pelas conversas intermináveis e hilárias no bar das freiras, e pelas ajudas que vocês me deram. Um abraço a todos e obrigado. Obrigado a todos! 


\section{RESUMO}

No presente trabalho será desenvolvido e avaliado um modelo matemático para determinar as propriedades termofísicas de nanofluidos formados a partir da combinação de nano partículas com gás refrigerante e óleo lubrificante, com aplicação no ciclo de refrigeração por compressão a vapor. O modelo levará em conta correlações empíricas para diferentes nanopartículas, baseadas em pesquisa bibliográfica realizada sobre refrigerantes e nanolubrificantes. Com base no cálculo das propriedades termofísicas dos nanofluidos, será proposta uma análise termodinâmica para avaliar o efeito deste fluido de trabalho no ciclo de refrigeração por compressão de vapor.

Palavras-chave: Refrigeração, nanopartícula, nanolubrificantes, refrigerante, nanofluidos. 


\begin{abstract}
A mathematical model is developed for determining the termophysical properties of nanofluids formed from the combination of nanoparticles with refrigerant gas and lubricant oil, with application in the vapor compression refrigeration cycle. The model takes into account empirical correlations for different nanoparticles, based on literature survey on refrigerants and nanolubrificants. Based on the calculation of the termophysical properties of the nanofluids, a thermodynamic analysis is carried out to evaluate the effect of these nanofluids in vapor compression refrigeration cycle.
\end{abstract}

Keywords: Nanofluids, refrigerants, refrigeration, nanolubricants, nanoparticles. 


\section{Sumário}

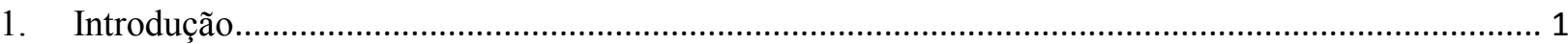

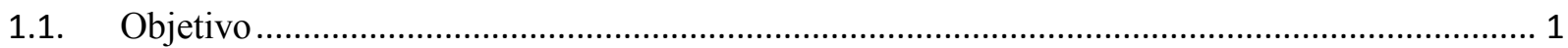

1.2. Propriedades da mistura refrigerante - nano-óleo no sistema de refrigeração .............................. 1

1.3. Organização do trabalho....................................................................................................... 3

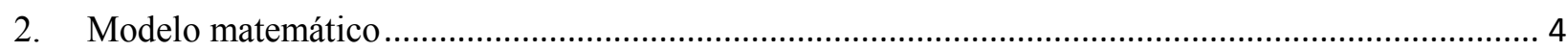

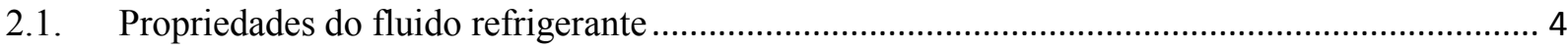

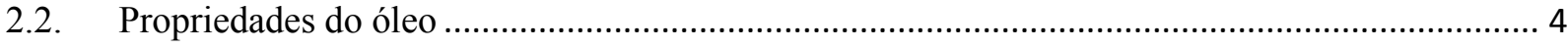

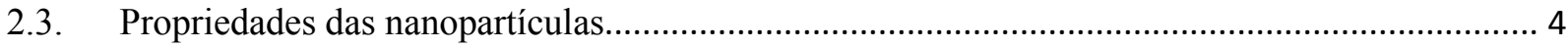

2.4. Propriedades do lubrificante ou nano-óleo (óleo e nanopartículas.............................................. 9

2.5. Propriedades da mistura nano-óleo - Refrigerante (nanofluido)............................................. 12

3. Modelo Termodinâmico do ciclo de refrigeração ............................................................................. 14

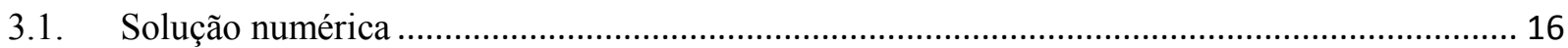

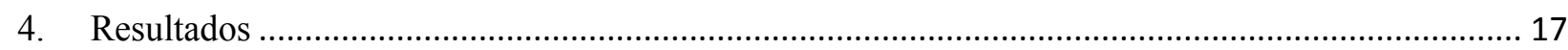

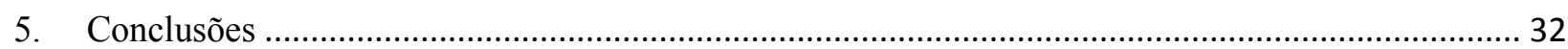

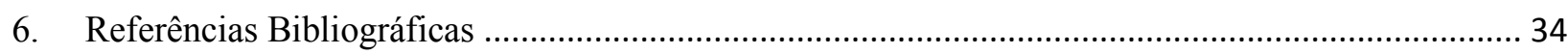




\section{LISTA DE FIGURAS}

Figura 1 - Diagrama P-h e ciclo de refrigeração por compressão a vapor ................................................ 14

Figura 2 - Fluxograma com a metodologia de resolução do modelo matemático..................................... 16

Figura 3 - Erro percentual do teste A, com relação aos valores experimentais e teóricos. ........................ 19

Figura 4 - Erro percentual do teste B, com relação aos valores experimentais e teóricos.......................... 19

Figura 5 - Trabalho compressor x Concentração do nano-óleo, para nanopartícula Alumina $\left(\mathrm{Al}_{2} \mathrm{O}_{3}\right) \ldots . . .21$

Figura 6 - Taxa de transferência de calor de condensação x Concentração do nano-óleo, para

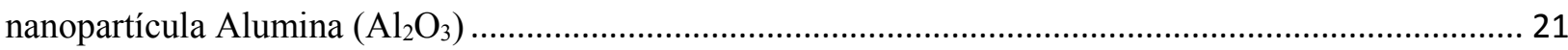

Figura 7 - Taxa de transferência de calor de evaporação x Concentração do nano-óleo, para nanopartícula

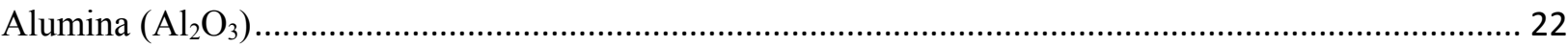

Figura 8 - Temperatura de descarga x Concentração do nano-óleo, para nanopartícula Alumina $\left(\mathrm{Al}_{2} \mathrm{O}_{3}\right) 23$ Figura 9 - Trabalho compressor x Concentração do nano-óleo, para nanopartícula de dióxidode Titânio

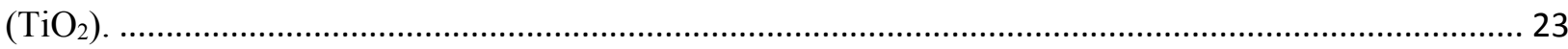

Figura 10 - Taxa de transferência de calor de condensação x Concentração do nano-óleo, para

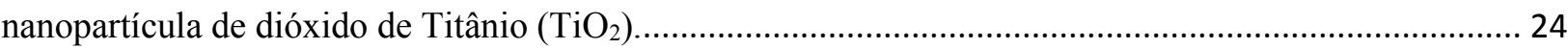

Figura 11 - Taxa de transferência de calor de evaporação x Concentração do nano-óleo, para

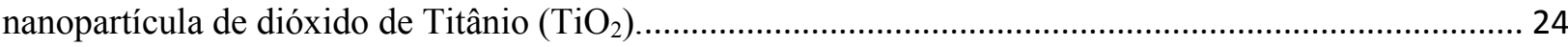

Figura 12 - Temperatura de descarga x Concentração do nano-óleo, para nanopartícula de dióxidode

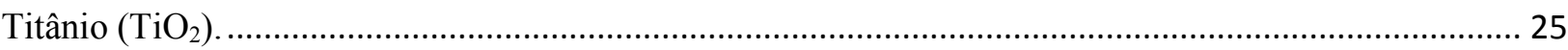

Figura 13 - Trabalho compressor x Concentração do nano-óleo, para nanopartícula de óxido de cobre

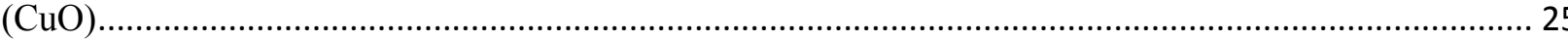

Figura 14 - Taxa de transferência de calor de condensação x Concentração do nano-óleo, para

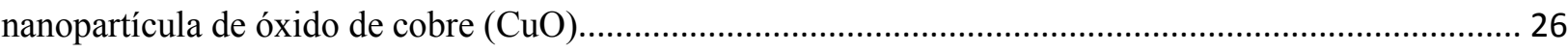

Figura 15 - Taxa de transferência de calor de evaporação x Concentração do nano-óleo, para

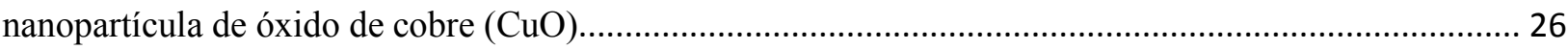
Figura 16 - Temperatura de descarga x Concentração do nano-óleo, para nanopartícula de óxido de cobre $(\mathrm{CuO})$

Figura 17 - Trabalho do compressor x Concentração do nano-óleo, para as três nanopartículas +R134a puro

Figura 18 - Taxa de transferência de calor de condensação x Concentração do nano-óleo, para as três nanopartículas $+\mathrm{R} 134$ a puro

Figura 19 - Taxa de transferência de calor de evaporação x Concentração do nano-óleo, para as três nanopartículas $+\mathrm{R} 134 \mathrm{a}$ puro

Figura 20 - Temperatura de descarga x Concentração do nano-óleo, para as três nanopartículas +R134a

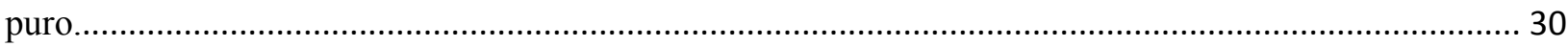

Figura 21 - Vazão mássica para: R134a; Al2O3; TiO2; CuO................................................................ 31 


\section{LISTA DE TABELAS}

Tabela 1 - Condutividade térmica de vários líquidos e sólidos a $300 \mathrm{~K}$ (Wang et al. 2007) ..................... 2

Tabela 2 - Dados experimentais Teste A (Fedele et al. ,2014)............................................................. 17

Tabela 3 - Dados experimentais Teste B (Fedele et al. ,2014) ............................................................... 18 


\section{NOMENCLATURA}

$c_{p} \quad$ Calor específico a pressão constante

$J / k g \cdot K$

$h \quad$ Entalpia

$\mathrm{kJ} / \mathrm{kg}$

$k \quad$ Condutividade térmica

$W / m \cdot K$

m $\quad$ Vazão mássica

$\mathrm{kg} / \mathrm{s}$

G Gravidade específica

$S \quad$ Entropia

$k J / k g K$

\section{Letras gregas}

$\mu \quad$ Viscosidade

$m P a \cdot s$

$\rho \quad$ Densidade

$\mathrm{kg} / \mathrm{m}^{3}$

$\varphi \quad$ Fração volumétrica

$\%$

$\omega$ Concentração de nanopartícula,

$\%$

\section{Subscritos}

np Nanopartícula

nf Nanofluido

no Nano-óleo

W concentração do nano-óleo 


\section{Introdução}

\subsection{Objetivo}

O presente trabalho tem como objetivo estudar a utilização da mistura refrigerante nano-óleo (nanofluido), com diferentes nanopartículas, como fluido térmico em um sistema de refrigeração por compressão a vapor. É utilizado um modelo matemático desenvolvido para comparação das taxas de transferência de calor e realização de trabalho, utilizando nanofluidos com $\mathrm{Al}_{2} \mathrm{O}_{3}, \mathrm{TiO}_{2}$ e $\mathrm{CuO}$. Por meio de análise comparativa dos resultados calculados pelo modelo matemático com os resultados experimentais obtidos na literatura foi possível validar o modelo. Tendo feito isto, também é feita uma análise de sensibilidade para estudar o efeito nos valores de transferência de calor e a tendência para diferentes concentrações de nanoparticula e óleo.

\subsection{Propriedades da mistura refrigerante - nano-óleo no sistema de refrigeração}

A maneira convencional para a melhoria na taxa de transferência de calor, que compreende no aumento da área de troca do mesmo no evaporador e condensador, nem sempre é viável, pois esbarra no problema de limitação de espaço e do aumento do consumo de energia. Nos dias de hoje, a busca e necessidade de novos fluídos refrigerantes com maiores condutividades térmicas é constante. Estes fluidos caracterizam-se por apresentarem propriedades termodinâmicas favoráveis, baixa toxicidade, serem não inflamáveis, compatíveis com materiais, boa estabilidade química e baixo impacto ambiental.

É sabido que metais sólidos possuem uma grande condutividade térmica quando comparados aos fluidos. Diante deste fato, é esperado que, ao utilizar fluidos com partículas sólidas suspensas, sua condutividade térmica, efetividade, seja maior do que a de fluidos 
convencionais. As partículas não devem possuir grandes dimensões, pois ocasionaria deposição dos metais no sistema (Yu et al., 2007).

Deste modo, desde a década passada, vem sendo pesquisada uma nova classe de fluidos, os denominados nanofluidos (Choi, 1995). Denomina-se nanofluido uma suspensão de nanopartículas num fluido base. O conceito de nanofluido emerge do campo da Nanotecnologia, (Withrama, 2003). Os nanofluidos são fluidos térmicos obtidos da suspensão de partículas de tamanho nanométrico (com dimensões entre $1 \mathrm{~nm}$ a $100 \mathrm{~nm}$ ) em fluidos convencionais de transferência de calor, usualmente líquidos (Yu et al, 2007).

Estes líquidos têm mostrado capacidade de troca de calor superior à dos fluidos convencionais (provavelmente, devido à maior ordem de grandeza da condutividade térmica dos sólidos, quando comparada à dos líquidos, como pode ser observado na Tab. 1).

\begin{tabular}{lll}
\hline & Material & Condutividade Térmica (W/m K) \\
\hline Sólides Metálicos & Cobre & 401 \\
& Alumínio & 237 \\
Sólides Não Metálicos & Silício & 148 \\
& Alumina $\left(\mathrm{Al}_{2} \mathrm{O}_{3}\right)$ & 40 \\
Líquidos Metálicos & Sódio (644 $\mathrm{K})$ & 72,3 \\
Líquidos Não Metálicos & Água & 0,613 \\
& Etileno glicol & 0,253 \\
& Óleo de Motor & 0,145 \\
\hline
\end{tabular}

Tabela 1 - Condutividade térmica de vários líquidos e sólidos a $300 \mathrm{~K}$ (Wang et al. 2007) 


\subsection{Organização do trabalho}

No capítulo 2 do presente trabalho, é apresentado o cálculo das propriedades termodinâmicas da mistura nanopartícula, óleo e refrigerante, No capítulo 3, é descrito o modelo termodinâmico do ciclo de refrigeração. Seguindo para o capítulo 4, chegamos aos resultados encontrados, onde é feita a validação do modelo termodinâmico e, em seguida, uma análise de sensibilidade. Finalmente, no capítulo 5 estão as conclusões observadas após todas as análises feitas e resultados obtidos. 


\section{Modelo matemático}

\subsection{Propriedades do fluido refrigerante}

$\mathrm{O}$ cálculo das propriedades do fluido refrigerante, condutividade térmica $\left(k_{r}\right)$, a viscosidade dinâmica $\left(\mu_{r}\right)$, o calor específico $\left(c_{p, r}\right)$ e a massa específica $\left(\rho_{r}\right)$, é efetuado diretamente em função da temperatura e pressão $\left(\mathrm{T}_{\mathrm{r}}, \mathrm{P}_{\mathrm{r}}\right)$, utilizando a biblioteca de propriedades termofísicas do software EES (Engineering Equation Solver) :

$$
\begin{aligned}
& \rho_{r}=\rho_{r}\left(T_{r}, P_{r}\right) \\
& \mu_{r}=\mu_{r}\left(T_{r}, P_{r}\right), k_{r}=k_{r}\left(T_{r}, P_{r}\right) \\
& c_{p, r}=c_{p, r}\left(T_{r}, P_{r}\right)
\end{aligned}
$$

\subsection{Propriedades do óleo}

Os cálculos das propriedades do óleo foram feitos a partir de correlações baseadas em testes experimentais

\section{Massa específica}

A massa especifica do óleo puro $\left(\rho_{o l}\right)$ em função da temperatura $(T)$ é mediante a correlação proposta por Kedzierski (1993):

$$
\rho_{o}=C_{o, 0}+C_{o, 1} T+C_{o, 2} T^{2}
$$


onde $\mathrm{T}=322 \mathrm{~K}$ e $C_{o, 0}=1,023 \times 10^{3}, C_{o, 1}=1,994 \times 10^{-1}$ e $C_{o, 2}=-1,318 \times 10^{-3}$, são coeficientes da correlação proposta por Kedzierski (1993).

\section{II.Calor Específico}

O calor específico do óleo pela equação proposta por Liley e Gambill (1973), para uma faixa de aplicação entre 263,15 K e 353,15 K, é dado por:

$$
c_{p, o l}=4,186\left(\frac{0,388+0,00045(1,8 T+32)}{\sqrt{G_{r, o l}}}\right)
$$

onde $G_{r, o l}$ é a gravidade específica do óleo, para valores de 0,75 até 0,96 , e seu cálculo é feito a partir da seguinte equação:

$$
\begin{gathered}
G_{r, o l}=\frac{\rho_{o l}}{\rho_{\text {água }}} \\
\text { e } \rho_{\text {água }}=999 \mathrm{~kg} / \mathrm{m}^{3} \text { a } T=288,71 \mathrm{~K},(\text { Conde, } 1997) .
\end{gathered}
$$

\section{Condutividade Térmica}

A condutividade térmica do óleo é calculada a partir da correlação proposta por Liley e Gambill (1973) em função da temperatura $T\left({ }^{\circ} \mathrm{C}\right)$

$$
k_{o l}=\frac{0,1172}{G_{r, o l}}(1-0,0054 T)
$$

\section{Viscosidade Dinâmica}

A viscosidade dinâmica do óleo é calculada mediante a correlação proposta por Guzman e Andrade (1930), em função da temperatura $T(K)$.

$$
\mu_{o l}=B e^{\frac{C}{T}}
$$


onde B e C são coeficientes com valores $1,364 \times 10^{-10}$ e 4,229 x $10^{3}$, respectivamente. De acordo com o trabalho apresentado pelo Kedzierski and Kaul (1993) os valores de B e C podem mudar segundo o tipo de óleo.

\section{Entalpia específica}

Para o cálculo da entalpia específica do óleo utilizamos a equação proposta por Lottin et al. (2003) mostrada abaixo.

$$
h_{o l}=\frac{4,186}{G_{r, o l}^{0,5}}\left(0,4024 T+0,000405 T^{2}\right)
$$

\section{Entropia específica}

A entropia específica do óleo é calculada de acordo com a correlação proposta por Vasconcelos et al. (2014).

$$
S_{o l}=\frac{4,186}{G_{r, o l}{ }^{0,5}}(-2,47872+0,00081 T+0,4024 \ln (T))
$$

onde a temperatura $\mathrm{T}$ é dada em $\mathrm{K}$.

\subsection{Propriedades da nanopatícula}

Assim como as propriedades do óleo foram calculadas a partir de correlações baseadas em testes experimentais, as propriedades das nanopartículas são igualmentes calculadas.

\subsubsection{Propriedades da nanopartícula de óxido de alumínio $\left(\mathrm{Al}_{2} \mathrm{O}_{3}\right)$}

I. Massa específica $\left(\rho_{\mathrm{Al}_{2} \mathrm{O}_{3}}\right)$ : Foi estimado para nanopartículas esféricas de 30nm de diâmetro foi obtido por Chandrasekar et al. (2010).

$$
\rho_{A l_{2} O_{3}}=3880\left(\mathrm{~kg} / \mathrm{m}^{3}\right)
$$


II. Calor Específico $\left(c_{p, A l_{2} O_{3}}\right)$ : Utilizando a correlação proposta por Wang et al. (2001), o calor específico foi calculado em função da temperatura $T(K)$, para uma faixa dentre $78 \mathrm{~K}$ e $370 \mathrm{~K}$, desenvolvida a partir de dados experimentais disponíveis na literatura.

$$
\begin{aligned}
\left(c_{p, A l_{2} O_{3}}\right) & =64,5451+53,6264 Y+8,2562 Y^{2}+14,0021 Y^{3}-8,1949 Y^{4}-18,849 \\
Y & =\frac{(T-224)}{146}
\end{aligned}
$$

III. Condutividade Térmica $\left(k_{\mathrm{Al}_{2} \mathrm{O}_{3}}\right)$ : Obtida através da correlação proposta por Pabst e Gregorová (2007), em função da temperatura para uma faixa de $0^{\circ} \mathrm{C}$ e $400^{\circ} \mathrm{C}$.

$$
k_{p, A l_{2} O_{3}}=3645(T+194)^{-0,874}
$$

IV. Entalpia específica $\left(h_{A l_{2} O_{3}}\right)$ : é obtida em função da temperatura $T(K)$ através da correlação do método Rutledge (1932).

$$
h_{\mathrm{Al}_{2} \mathrm{O}_{3}}=c_{p, A l_{2} O_{3}}(T-273,15)
$$

V. Entropia específica $\left(s_{\mathrm{Al}_{2} \mathrm{O}_{3}}\right)$ : Obtida em função da temperatura $\mathrm{T}(\mathrm{K})$ pela correlação Simpson Ruler.

$$
S_{\mathrm{Al}_{2} \mathrm{O}_{3}}=c_{p, A l_{2} \mathrm{O}_{3}}(\ln (T)-273,15)
$$

\subsubsection{Propriedades da nanopartícula de dióxido de titânio $\left(\mathrm{TiO}_{2}\right)$}

I. Massa específica $\left(\rho_{\mathrm{TiO}_{2}}\right)$ : É utilizado um valor constante para nanopartículas esféricas de $30 \mathrm{~nm}$ de diâmetro, obtido por Mahbubul et al. (2013).

$$
\rho_{\mathrm{TiO}_{2}}=4260\left(\mathrm{~kg} / \mathrm{m}^{3}\right)
$$


II. Calor específico $\left(c_{p, \mathrm{TiO}_{2}}\right)$ : É obtido através da curva experimental apresentada por Saeedian et al. (2013). Esta curva é um polinômio em função da temperatura $T(K)$, onde se opera dentro da faixa de $70 \mathrm{~K}$ e $370 \mathrm{~K}$.

$$
c_{p, T i O_{2}}=-1,070 E^{-12} T^{5}+1,224 E^{-9} T^{4}-5,082 E^{-7} T^{3}+8,970 E^{-5} T^{2}-2,370 E^{-3} T+0,018
$$

III. Condutividade térmica $\left(k_{\mathrm{TiO}_{2}}\right)$ : Para gerar a equação (19), foram utilizados os valores propostos pelo Weerapun e Somchai (2009), para uma faixa de temperatura de 288,15 K até $308,15 \mathrm{~K}$.

$$
k_{\mathrm{TiO}_{2}}=0,0155 T+13,098
$$

IV. Entalpia específica $\left(h_{\mathrm{TiO}_{2}}\right)$ : é obtida em função da temperatura $T(K)$ através da correlação do método Rutledge (1932).

$$
h_{\mathrm{TiO}_{2}}=c_{p, \mathrm{TiO}_{2}}(T-273,15)
$$

V. Entropia específica $\left(s_{\mathrm{TiO}_{2}}\right)$ : Obtida em função da temperatura $\mathrm{T}(\mathrm{K})$ pela correlação Simpson-Ruler.

$$
s_{\mathrm{TiO}_{2}}=c_{p, \mathrm{TiO}_{2}}(\ln (T)-273,15)
$$

\subsubsection{Propriedades da nanopartícula de óxido de Cobre (CuO)}

I. Massa específica ( $\left.\rho_{C u O}\right)$ : É utilizado o valor médio estimado por Kedzierski (2002), para nanopartículas esféricas de $30 \mathrm{~nm}$ de diâmetro, apresentado pela seguinte equação.

$$
\rho_{\text {CuO }}=5760\left(\mathrm{~kg} / \mathrm{m}^{3}\right)
$$


II. Calor específico $\left(c_{p, C u O}\right)$ : Baseado na correlação apresentada por Junod et al. (1989), o calor especifico das nanopartículas de óxido de cobre é calculado em função da temperatura, para valores de $78 \mathrm{~K}$ e $300 \mathrm{~K}$.

$$
c_{p, \text { CuO }}=0,2 E^{-9} T^{4}-1,254 E^{-7} T^{3}+2,287 E^{-5} T^{2}-0,238 E^{-3} T
$$

III. Condutividade térmica $\left(k_{C u O}\right)$ : Para gerar a equação (17), foram utilizados os valores propostos pelo Weerapun e Somchai (2009), para uma faixa de temperatura de 288,15 K até $308,15 \mathrm{~K}$.

$$
k_{\text {CuO }}=20(W / m-K)
$$

IV. Entalpia específica $\left(h_{C u O}\right)$ : é obtida em função da temperatura $T(K)$ através da correlação do método Rutledge (1932).

$$
h_{\text {CuO }}=c_{p, \text { CuO }}(T-273,15)
$$

V. Entropia específica $\left(s_{C u O}\right)$ : Obtida em função da temperatura $\mathrm{T}(\mathrm{K})$ pela correlação Simpson Ruler.

$$
s_{\text {CuO }}=c_{p, \text { CuO }}(\ln (T)-273,15)
$$

\subsection{Propriedades do lubrificante ou nano - óleo (óleo e nanopartículas)}

A mistura do óleo (fluido base) com nanopartículas $\left(\mathrm{Al}_{2} \mathrm{O}_{3}, \mathrm{TiO}_{2}\right.$ ou $\left.\mathrm{CuO}\right)$ é chamada de nanolubrificante ou nano-óleo. As propriedades do nanolubrificante são calculadas a partir das correlações encontradas na literatura. No presente trabalho convencionou-se o subscrito ( $n p$ ) para fazer referência às nanopartículas. 


\section{Massa específica $\left(\rho_{o l, n p}\right)$}

O cálculo da massa específica é baseado no principio de conservação de massa. É calculada em função da fração volumétrica das nanopartículas no óleo $\left(\varphi_{o l, n p}\right)$ e das massas específicas da nanopartícula $\left(\rho_{n p}\right)$ e do óleo $\left(\rho_{o l}\right)$, (Kwak et al. 2005).

$$
\rho_{o l, n p}=\left(1-\varphi_{o l, n p}\right) \rho_{o l}+\varphi_{o l, n p} \rho_{n p}
$$

\section{Calor específico $\left(c_{p, o l, n p}\right)$}

O calor específico é calculado a partir do príncipio de conservação de energia, assumindo-se o equilíbrio térmico entre as nanopartículas e óleo (Kwak et al. 2005). Com isso tem-se:

$$
c_{p, o l, n p}=\frac{\left(1-\varphi_{o l, n p}\right) \rho_{o l} C_{p, o l}+\varphi_{o l, n p} \rho_{n p} C_{p, n p}}{\rho_{o l . n p}}
$$

onde $\left(c_{p, o l}\right)$ é o calor específico do óleo, $\left(c_{p, n p}\right)$ é o calor específico da nanopartícula e $\left(\rho_{o l . n p}\right)$ é a massa específica do nano-óleo.

\section{Condutividade térmica $\left(k_{o l . n p}\right)$}

Pelo modelo de Hamilton e Crosser (1962), pode-se calcular a condutividade térmica para nanopartículas esféricas.

$$
k_{o l . n p}=k_{o l} \frac{k_{n p}+2 k_{o l}-2 \varphi_{o l . n p}\left(k_{o l}-k_{n p}\right)}{k_{n p}+2 k_{o l}+\varphi_{o l . n p}\left(k_{o l}-k_{n p}\right)}
$$

onde $\left(k_{o l}\right)$ é a condutividade térmica do óleo e $\left(k_{n p}\right)$ da nanopartícula. 


\section{Viscosidade dinâmica $\left(\mu_{o l . n p}\right)$}

Baseado na correlação apresentada por Brinkman (1952) a viscosidade é calculada em função da viscosidade do óleo $\left(\mu_{o l}\right)$ e da fração volumétrica das nanopartículas no óleo $\left(\varphi_{\text {ol.np }}\right)$

$$
\mu_{o l . n p}=\mu_{o l} \frac{1}{\left(1+\varphi_{o l . n p}\right)^{2,5}}
$$

\section{Fração volumétrica das nanopartículas no óleo $\left(\varphi_{o l . n p}\right)$}

A fração volumétrica é calculada em função da concentração da nanoparticula $\left(\omega_{n p}\right)$, da massa específica do óleo $\left(\rho_{o l}\right)$ e da massa específica da nanopartícula $\left(\rho_{n p}\right)$.

$$
\varphi_{n p}=\frac{\omega_{n p} \rho_{o l}}{\left(\omega_{n p} \rho_{o l}+\left(1-\omega_{n p}\right) \rho_{n p}\right)}
$$

\section{Entalpia específica $\left(h_{o l . n p}\right)$}

A entalpia específica do nano-óleo foi calculada mediante a correlação utilizada por Khalil Khanafer (2011).

$$
h_{o l . n p}=h_{n p} \omega_{n p}+\left(1-\omega_{n p}\right) h_{o l}
$$

\section{Entropia específica $\left(s_{o l . n p}\right)$}

Para o cálculo da entropia específica do nano-óleo utilizamos a equação proposta por Khalil Khanafer (2011).

$$
s_{o l . n p}=s_{n p} \omega_{n p}+\left(1-\omega_{n p}\right) s_{o l}
$$




\subsection{Propriedades da mistura nano-óleo - Refrigerante (Nanofluido)}

\section{Massa específica $\left(\rho_{n f}\right)$}

Através da equação proposta pelo Jensen and Jackman (1984), podemos calcular a massa específica, em função da concentração do nano-óleo na mistura $\left(w_{o l, n p}\right)$, massa específica do nano-óleo $\left(\rho_{o l, n p}\right)$ e da massa específica do fluido refrigerante $\left(\rho_{r}\right)$. A faixa de temperatura para o uso desta equação é de $-20^{\circ} \mathrm{C}$ até $80^{\circ} \mathrm{C}$.

$$
\rho_{n f}=\left[\frac{w_{o l, n p}}{\rho_{o l, n p}}+\left(\frac{1-w_{o l, n p}}{\rho_{r}}\right)\right]^{-1}
$$

\section{Calor específico $\left(c_{p, n f}\right)$}

Baseado na correlação apresentada por Jensen e Jackman (1984), o calor específico é calculado.

$$
c_{p, n f}=\frac{\left(1-w_{o l, n p}\right) c_{p, r} \rho_{r}+w_{o l, n p} c_{p, o l, n p} \rho_{o l, n p}}{\rho_{n f}}
$$

\section{Condutividade Térmica $\left(k_{n f}\right)$}

Mediante a correlação proposta e desenvolvida por Bastian et al. (1988) a condutividade térmica é calculada.

$$
k_{n f}=k_{r}\left(1-w_{o l, n p}\right)+\left(k_{o l, n p} w_{o l, n p}\right)-\left(0,72 w_{o l, n p}\left(1-w_{o l, n p}\right)\left(k_{o l, n p}-k_{r}\right)\right)
$$




\section{Viscosidade dinâmica $\left(\mu_{n f}\right)$}

A viscosidade da mistura é calculada pela correlação proposta por Kedzierski e Kaul (1993).

$$
\mu_{n f}=e^{\left.\left(w_{o l, n p} \ln \left(\mu_{o l, n p}\right)\right)+\left(1-w_{o l, n p}\right) \ln \left(\mu_{r}\right)\right)}
$$

\section{Entalpia específica $\left(h_{n f}\right)$}

A entalpia específica da mistura nano-óleo - refrigerante foi calculada mediante a correlação proposta por Wenjiam (2008), baseada nas entalpias na fase liquida e vapor do refrigerante.

$$
h_{n f}=\omega_{n o} h_{o l, n p}+\omega_{r, l} h_{r, l}+\omega_{r, v} h_{r, v}
$$

\section{Entropia específica $\left(s_{n f}\right)$}

A partir da equação proposta por Wenjian (2008), calculamos a entropia específica da mistura, onde também levou em consideração a entropia na fase liquida e vapor do refrigerante.

$$
s_{n f}=\omega_{n o} s_{o l, n p}+\omega_{r, l} s_{r, l}+\omega_{r, v} s_{r, v}
$$




\section{Modelo Termodinâmico do ciclo de refrigeração}

O ciclo termodinâmico de refrigeração por compressão a vapor foi utilizado para este projeto. Abaixo são apresentados o ciclo e seu correspondente no diagrama Pressão (P) x Entalpia (h). Pode-se analisar os pontos de entrada e saída e calcular as taxas de transferência de calor do condensador e evaporador, assim como a potência do compressor.
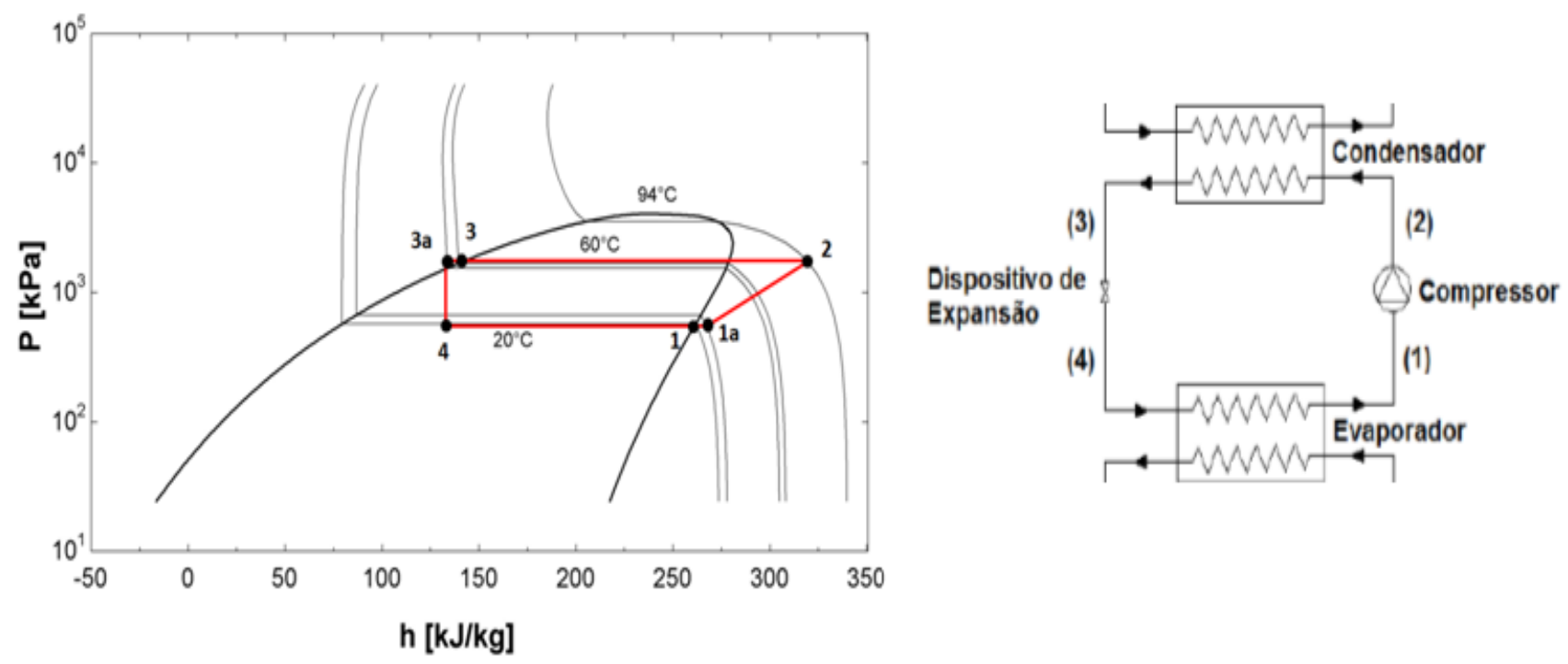

Figura 1 - Diagrama P-h e ciclo de refrigeração por compressão a vapor

\section{Evaporador (Ponto 4 - 1)}

Para o cálculo da taxa de transferência de calor do evaporador utilizamos a equação (34) baseada no balanço de energia.

$$
Q_{\text {evap }}=\dot{m}\left(h_{1}-h_{4}\right)
$$

onde $\dot{m}$ é a vazão mássica do fluido. 


\section{Condensador (Ponto 2 - 3)}

Para o cálculo da taxa de transferência de calor do evaporador utilizamos a mesma equação de balanço de energia utilizada no evaporador só que agora nos pontos 2 e 3 .

$$
Q_{\text {cond }}=\dot{m}\left(h_{2}-h_{3}\right)
$$

\section{Compressor (Ponto 1a - 2)}

Para o cálculo da potência do compressor (rotativo) também utilizamos a equação de balanço de energia, porém agora para os pontos 1a e 2 .

$$
W_{p}=\dot{m}\left(h_{2}-h_{1 a}\right)
$$

A entalpia no ponto 2 foi calculada a partir da equação abaixo:

$$
h_{2}=h_{1}+\frac{\left(h_{2 s}-h_{1}\right)}{\eta_{i s}}
$$

A vazão mássica foi calculada a partir da seguinte equação:

$$
\dot{m}=\rho_{1 a} \eta_{v o l} V_{d} r p s \alpha
$$

onde,

$V_{d}$ - Deslocamento volumétrico do compressor $\left(\mathrm{cm}^{3}\right)$

$\rho_{1 a^{-}}$- Densidade do fluido na entrada do compressor $\left(\mathrm{kg} / \mathrm{m}^{3}\right)$

rps - Rotações do compressor

$\alpha$ - Coeficientes de perda da vazão mássica 


\section{Válvula de expansão (Ponto 3a - 4)}

Para a expansão isoentálpica as entalpias no ponto 3 a e 4 são iguais.

$$
h_{3 a}=h_{4}
$$

\subsection{Solução Numérica}

O algoritmo para a solução do modelo matemático é apresentado a seguir.

Inserir os dados de operação do sistema (P1, P2,Tevap, Tcond, $\Delta \mathrm{Tsh}, \Delta \mathrm{Tsc}, \eta \_$is, $\eta \_$vol.)

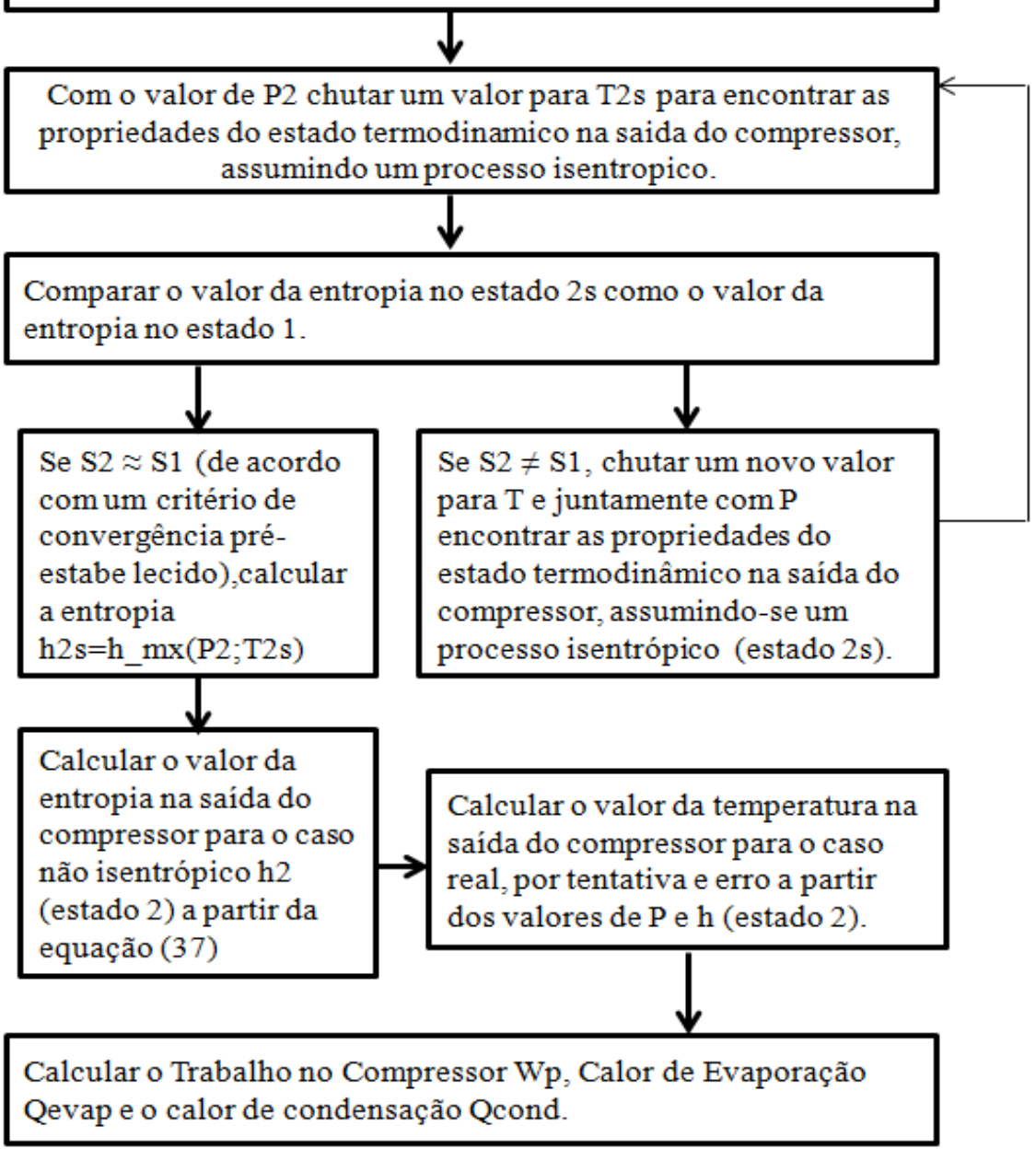

Figura 2 - Fluxograma com a metodologia de resolução do modelo matemático 


\section{Resultados}

\section{1-Validação do modelo termodinâmico do ciclo de refrigeração}

Nesta etapa será feita a comparação do modelo desenvolvido neste projeto com dados experimentais disponíveis na literatura.

Para a validação do modelo utilizamos o estudo experimental feito por Fedele et al. (2014), que fez uso da mesma mistura (óleo, nanopartìcula e R134a) presente neste projeto. Neste estudo foram feitos dois testes com diferentes temperaturas de condensação e de evaporação e variando a concentração da nanopartícula de dióxido de Titânio $\mathrm{TiO}_{2}$. Os testes realizados foram:

- Teste A: Temperatura de condensação igual a $60^{\circ} \mathrm{C}$ e de evaporação, $20^{\circ} \mathrm{C}$.

- Teste B: Temperatura de condensação igual a $52,5^{\circ} \mathrm{C}$ e de evaporação, $19^{\circ} \mathrm{C}$.

Os resultados obtidos nos testes estão mostrados abaixo:

\begin{tabular}{|c|c|c|c|c|c|c|c|c|c|c|}
\hline Teste A & $\begin{array}{l}\text { SH } \\
{\left[{ }^{\circ} \mathbf{C}\right]}\end{array}$ & $\begin{array}{r}\mathrm{SC} \\
{\left[{ }^{\circ} \mathrm{C}\right]}\end{array}$ & $\begin{array}{l}\text { Qcond } \\
{[\mathrm{kW}]}\end{array}$ & $\begin{array}{c}\text { Qw_cond } \\
{[\mathrm{kW}]}\end{array}$ & $\begin{array}{r}\text { Qevap } \\
{[\mathrm{kW}]}\end{array}$ & $\begin{array}{c}\mathbf{Q}_{\mathbf{w} \_ \text {evap }} \\
{[\mathrm{kW}]}\end{array}$ & $\begin{array}{c}\mathrm{COPH} \\
{[-]}\end{array}$ & $\begin{array}{c}\mathrm{COPC} \\
{[-]}\end{array}$ & $\boldsymbol{\eta}_{i s}$ & $\begin{array}{r}\boldsymbol{\eta}_{\text {vol }} \\
\text { [-] }\end{array}$ \\
\hline $\begin{array}{c}\text { POE com } \\
0,1 \% \text { de } \mathrm{TiO}_{2}\end{array}$ & 5,22 & 3,66 & 1,38 & 1,34 & 1,12 & 1,17 & 3,97 & 3,23 & 0,73 & 0,86 \\
\hline $\begin{array}{c}\text { POE com } \\
0,5 \% \text { de } \mathrm{TiO}_{2}\end{array}$ & 4,77 & 3,97 & 1,38 & 1,35 & 1,12 & 1,16 & 3,98 & 3,23 & 0,71 & 0,85 \\
\hline
\end{tabular}

Tabela 2 - Dados experimentais Teste A (Fedele et al. ,2014) 


\begin{tabular}{|c|c|c|c|c|c|c|c|c|c|c|}
\hline Teste B & $\begin{array}{c}\mathrm{SH} \\
{\left[{ }^{\circ} \mathrm{C}\right]}\end{array}$ & $\begin{array}{c}\mathrm{SC} \\
{\left[{ }^{\circ} \mathrm{C}\right]}\end{array}$ & $\begin{array}{l}Q_{\text {cond }} \\
{[\mathrm{kW}]}\end{array}$ & $\begin{array}{c}\mathbf{Q}_{\mathbf{w}} \text { cond } \\
{[\mathbf{k W}]}\end{array}$ & $\begin{array}{l}\text { Qevap } \\
{[k W]}\end{array}$ & $\begin{array}{c}\mathbf{Q}_{\mathbf{w} \_ \text {evap }} \\
{[\mathbf{k W ]}}\end{array}$ & $\begin{array}{c}\mathrm{COP}_{\mathrm{H}} \\
{[-]}\end{array}$ & $\begin{array}{c}\mathrm{COP}_{\mathrm{C}} \\
{[-]}\end{array}$ & $\eta_{i s}$ & $\begin{array}{c}\eta_{\text {vol }} \\
{[-]}\end{array}$ \\
\hline $\begin{array}{c}\text { POE com } \\
0,1 \% \text { de } \mathrm{TiO}_{2}\end{array}$ & 3,80 & 4,68 & 1,46 & 1,43 & 1,22 & 1,26 & 4,85 & 4,06 & 0,71 & 0,89 \\
\hline $\begin{array}{c}\text { POE com } \\
0,5 \% \text { de } \mathrm{TiO}_{2}\end{array}$ & 5,01 & 5,20 & 1,46 & 1,43 & 1,23 & 1,25 & 4,83 & 4,07 & 0,71 & 0,89 \\
\hline
\end{tabular}

Tabela 3 - Dados experimentais Teste B (Fedele et al. ,2014)

Com isso foi possível fazer a comparação com os dados experimentais e os calculados, a partir do modelo. Obtendo os gráficos com o erro percentual para cada teste.

No gráfico da figura 3 está plotado o erro percentual dos valores de taxa de transferência de calor do evaporador e do condensador e o trabalho do compressor, calculados a partir do modelo matemático descrito no presente projeto, em relação aos valores dos testes executados no artigo de Fedele et al. (2014). O erro máximo encontrado no teste A foi de $11,37 \%$ relacionado ao trabalho do compressor o qual para nossas aplicações, é um valor pequeno, podendo ser explicado devido a algumas correlações aproximadas que foram utilizadas, como por exemplo, a própria equação de balanço de energia, que para esse compressor pode ser uma equação simplificada para o cálculo (não prevê a troca de calor com o meio externo). E também por aproximações de outros valores. 


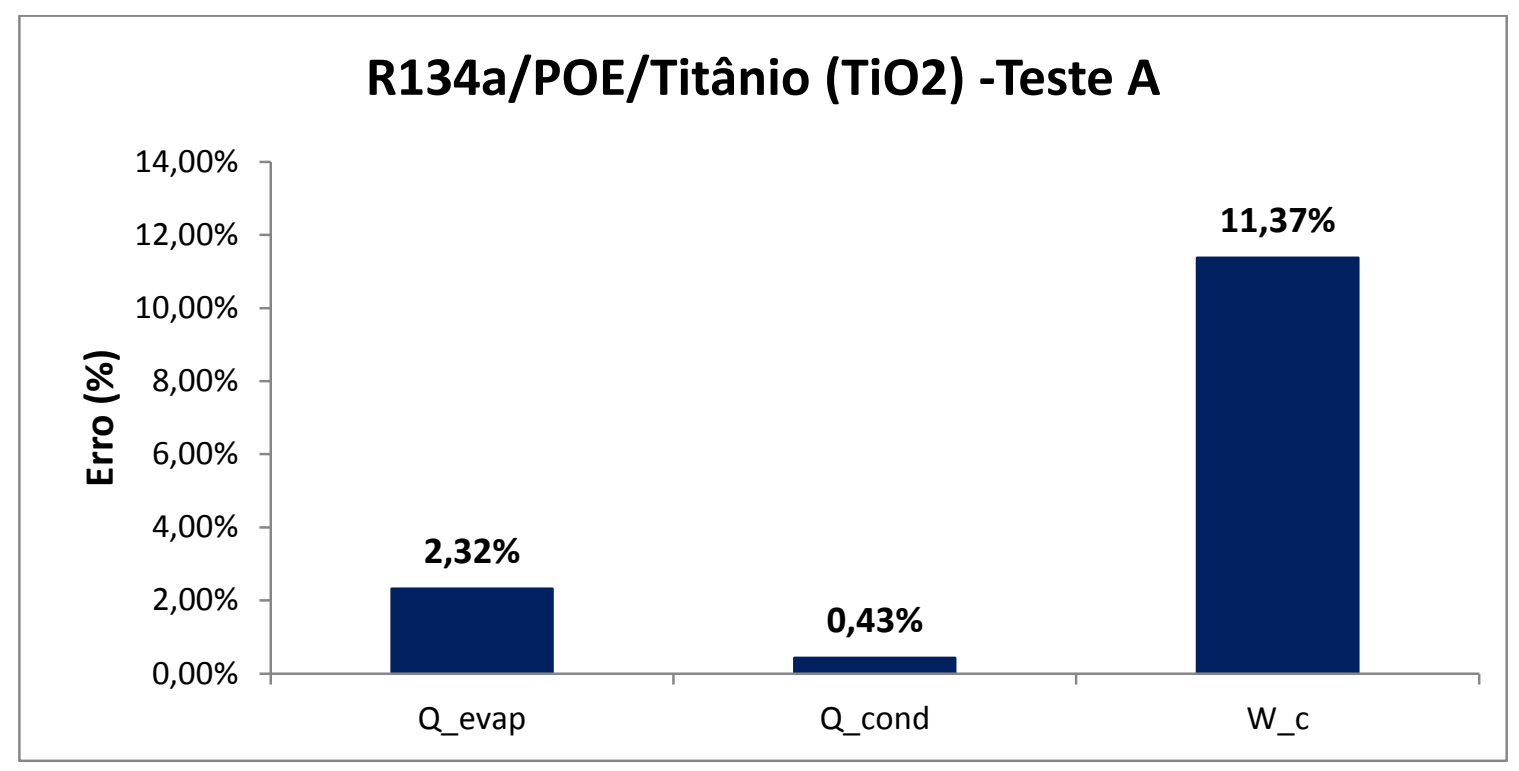

Figura 3 - Erro percentual do teste A, com relação aos valores experimentais e teóricos.

Já para o gráfico da figura 4 obtivemos, no teste $B$, um erro máximo de $12,54 \%$ referente ao trabalho no compressor. Para as nossas aplicações é um valor pequeno, onde pode ter sido dado devido a algumas correlações aproximadas que utilizamos e ou valores aproximados utilizados. O mesmo ocorreu para o erro de 6,85\%, referente à taxa de transferência de calor do condensador.

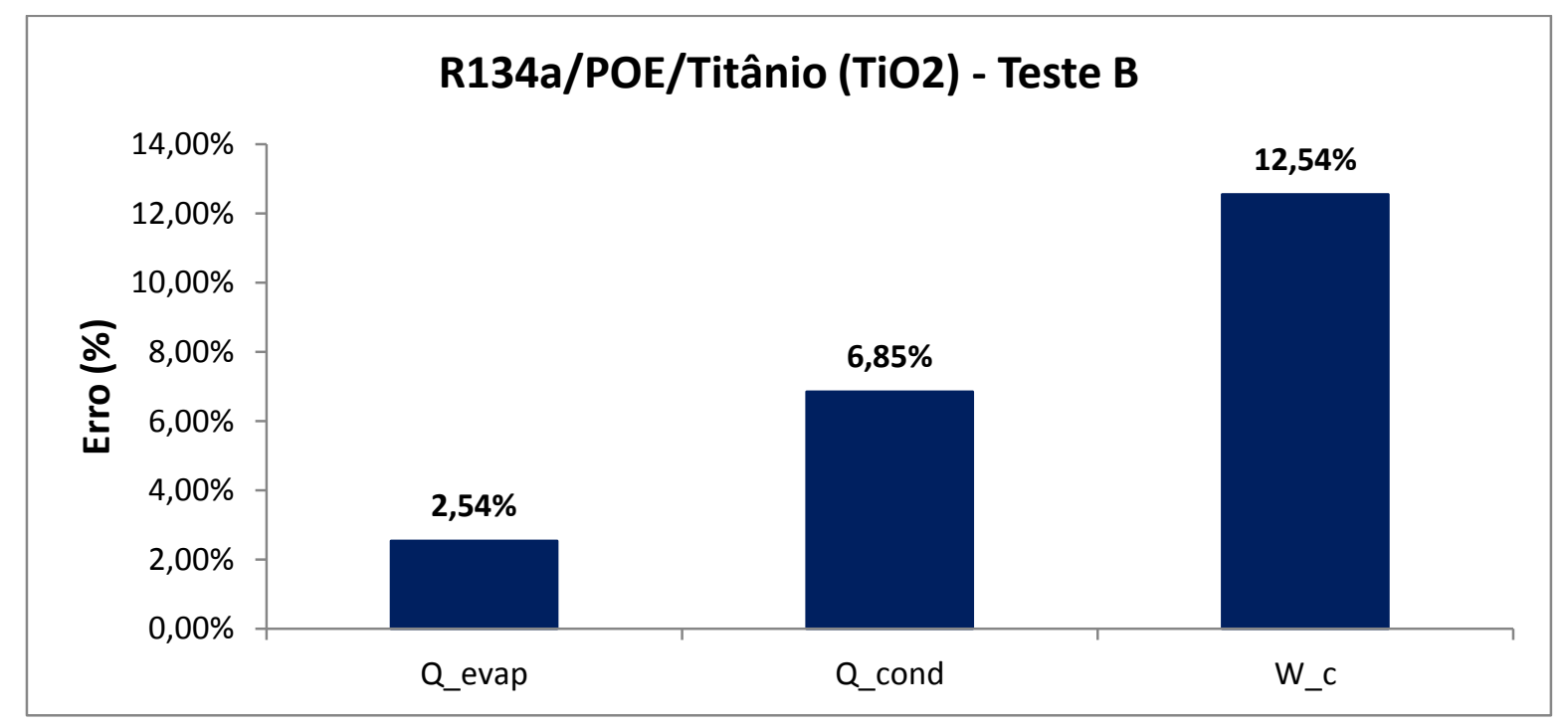

Figura 4 - Erro percentual do teste B, com relação aos valores experimentais e teóricos. 
Com os valores dos erros baixos e sabendo onde possa estar o motivo da discrepância elevada no compressor, pudemos dar o modelo matemático como validade e seguir para a próxima etapa, onde será feita a analise de sensibilidade do projeto.

\section{2-Análise de sensibilidade}

A seguir, estudaremos a aplicabilidade do método mediante o uso da análise de sensibilidade. Para isso, utilizamos as três nanopartículas estudadas neste projeto, Alumina $\left(\mathrm{Al}_{2} \mathrm{O}_{3}\right)$, dióxido de Titânio $\left(\mathrm{TiO}_{2}\right)$ e óxido de Cobre $(\mathrm{CuO})$, com concentrações, $\left(\omega_{\mathrm{n}}\right)$, de $(1 ; 5$; 10\%). As concentrações mássicas de óleo ( $\left.\mathrm{W}_{\mathrm{no}}\right)$ POE RL68H utilizadas foram $(5 ; 6 ; 7 ; 8 ; 9 ; 10$; $11 ; 12 ; 13 ; 14 \%)$. Consideramos, também, as eficiências isentrópicas e volumétricas como sendo iguais a 1 .

O gráfico da figura 5 mostra a variação do trabalho do compressor $\left(W_{p}\right)$ para diferentes concentrações da nanopartícula de alumina e concentração de nano-óleo, incluindo o refrigerante R134a puro. Podemos ver que, com o aumento da concentração do nano-óleo, há um ponto máximo do valor do trabalho do compressor. Ao aumentar a concentração da nanopartícula, observa-se um aumento no trabalho do compressor. O aumento seguido de queda pode dar lugar a outra tendência caso outro fator, que não levamos em consideração no presente projeto, como por exemplo, a solubilidade, fosse considerada. A solubilidade apresenta grande relação entre as temperaturas de evaporação e condensação a concentração do óleo. Talvez, o uso desta propriedade tenha maior efeito no compressor onde a quantidade de óleo é maior. 


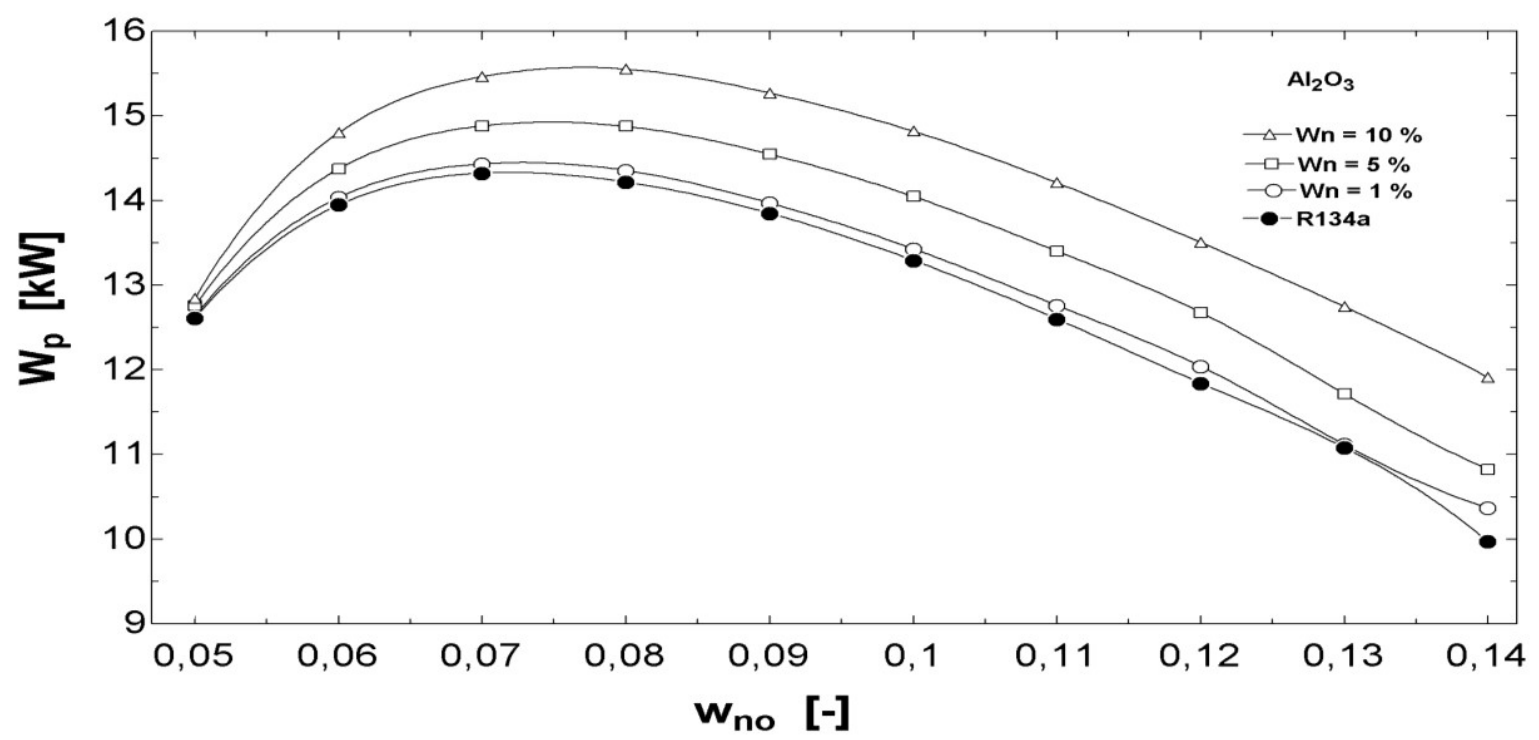

Figura 5 - Trabalho compressor x Concentração do nano-óleo, para nanopartícula Alumina $\left(\mathrm{Al}_{2} \mathrm{O}_{3}\right)$

O gráfico da figura 6 abaixo mostra a variação da taxa de transferência de calor com condensação $\left(Q_{\text {cond }}\right)$ para diferentes concentrações da nanopartícula de alumina e para o refrigerante R134a puro, ou com a variação de concentração mássica do nano-óleo. Observou-se uma tendência de decréscimo na taxa de transferência de calor de condensação $\left(Q_{c o n d}\right)$ com o aumento da concentração de nano-óleo. E, à medida que aumenta a concentração da nanopartícula de alumina vemos que $\left(Q_{\text {cond }}\right)$ também aumenta.

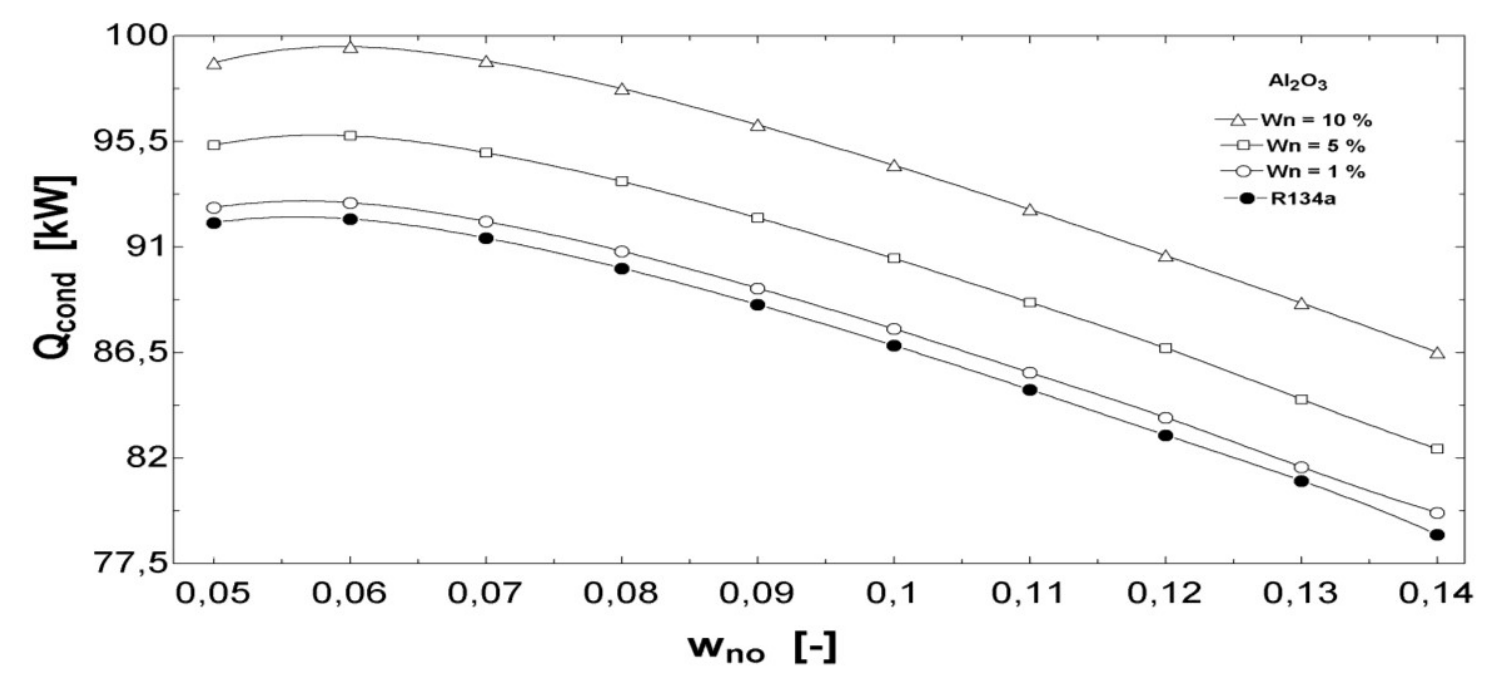

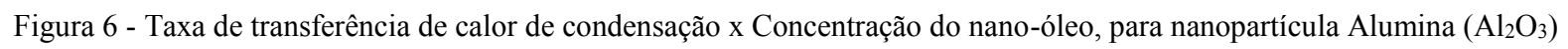


Na figura 7 temos o gráfico mostrando a variação da taxa de transferência de calor de evaporação $\left(Q_{\text {evap }}\right)$ para diferentes concentrações da nanopartícula de alumina e para o refrigerante R134a puro, com a variação do nano-óleo. Assim como o ocorrido com $\left(Q_{\text {cond }}\right)$, a taxa de transferência de calor de evaporação também possui a tendência de queda com o aumento da concentração do nano-óleo. Ao aumentarmos a concentração da nanopartícula de alumina conseguimos uma elevação do $\left(Q_{\text {evap }}\right)$.

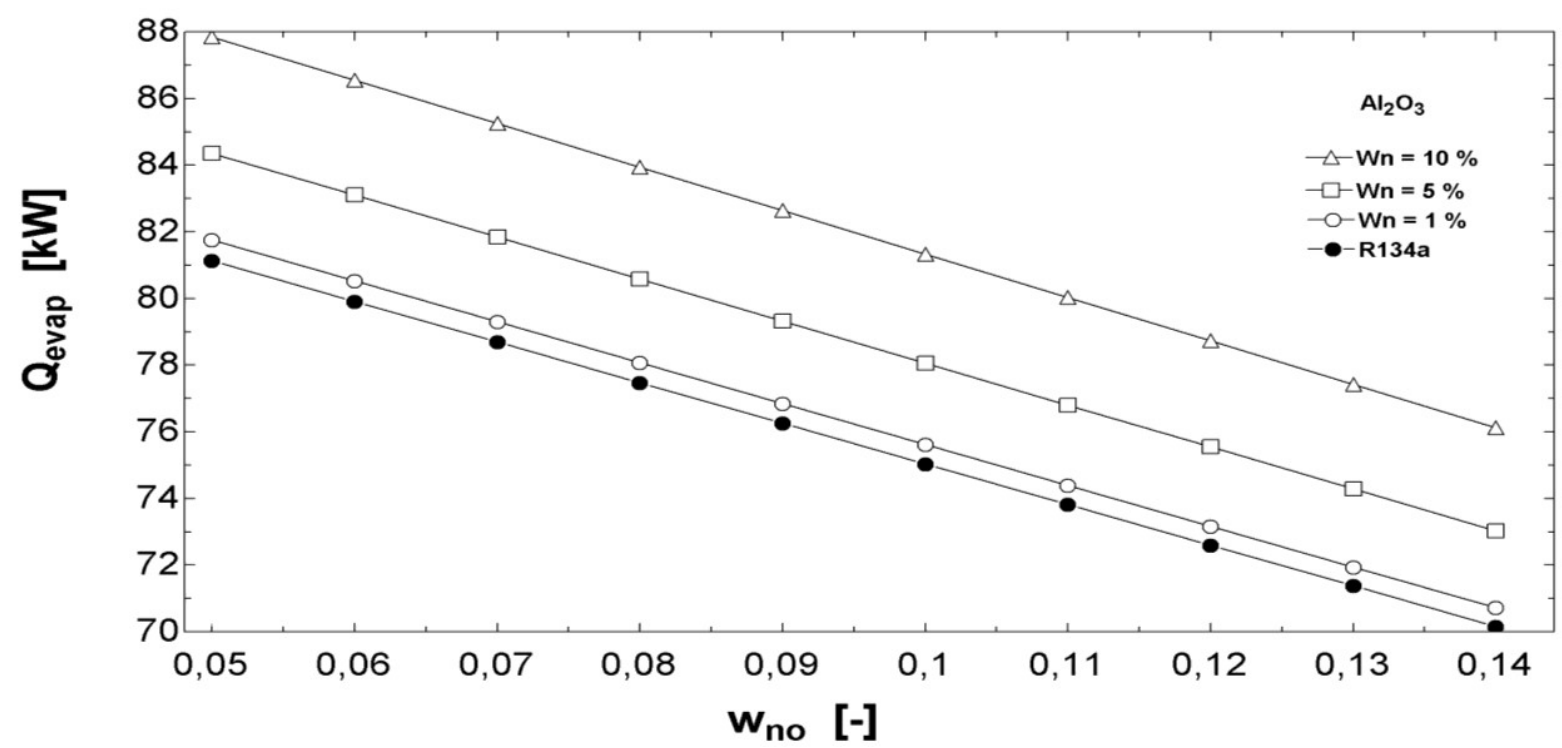

Figura 7 - Taxa de transferência de calor de evaporação x Concentração do nano-óleo, para nanopartícula Alumina $\left(\mathrm{Al}_{2} \mathrm{O}_{3}\right)$

$\mathrm{Na}$ figura 8 avaliamos a tendência da temperatura da descarga no compressor $\left(T_{\text {des }}\right)$, com a variação da concentração do nano-óleo para diferentes concentrações da nanopartícula de alumina e para o refrigerante R134a puro. Podemos observar um aumento na temperatura de descarga até uma faixa de temperatura entre $85^{\circ} \mathrm{C}$ e $90^{\circ} \mathrm{C}$. Após isso vemos que a temperatura tende a diminuir. Isso se deve ao fato de que compressores, segundo os fabricantes, trabalham em uma faixa de temperatura de até $90^{\circ} \mathrm{C}$ e, com isso, a nossa faixa de observação no gráfico fica restrita até esta temperatura. Observou-se também uma pequena variação da temperatura quando aumentada a concentração da nanopartícula. 


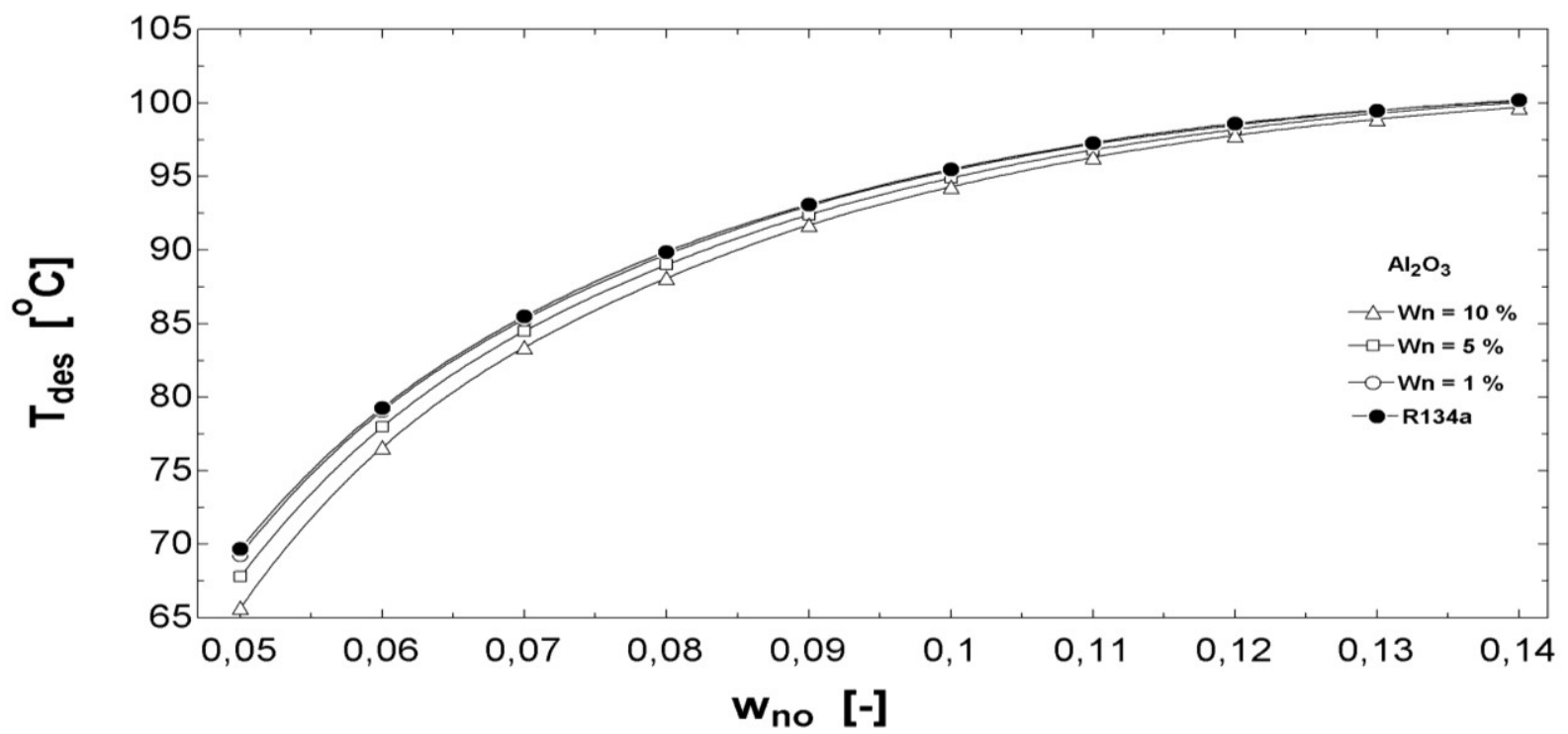

Figura 8 - Temperatura de descarga x Concentração do nano-óleo, para nanopartícula Alumina $\left(\mathrm{Al}_{2} \mathrm{O}_{3}\right)$

Para os passos seguintes analisamos os mesmos gráficos representados acima para as nanopartículas de dióxido de titânio $\left(\mathrm{TiO}_{2}\right)$ e óxido de cobre $(\mathrm{CuO})$ e o comportamento observado foi o mesmo, como mostrado abaixo.

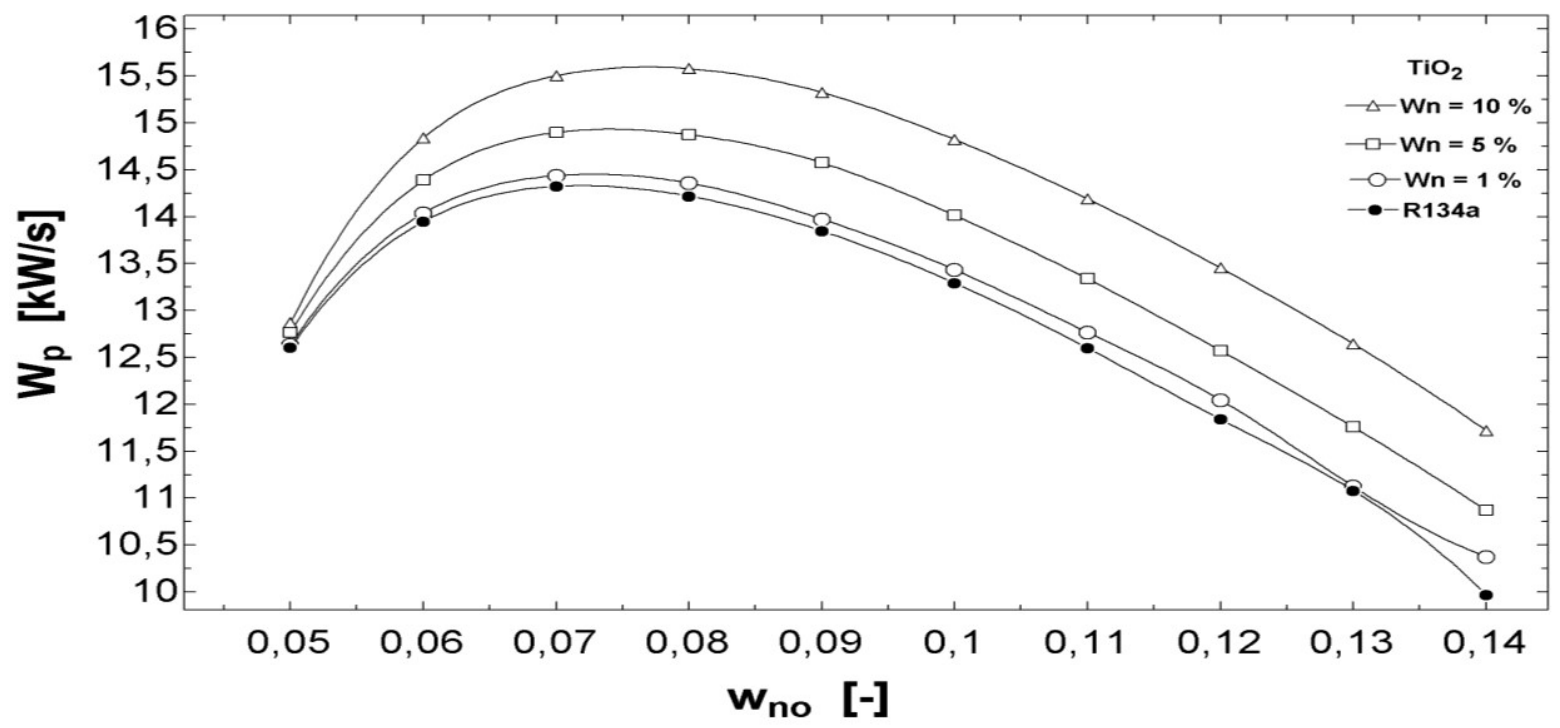

Figura 9 - Trabalho compressor x Concentração do nano-óleo, para nanopartícula de dióxidode Titânio $\left(\mathrm{TiO}_{2}\right)$. 


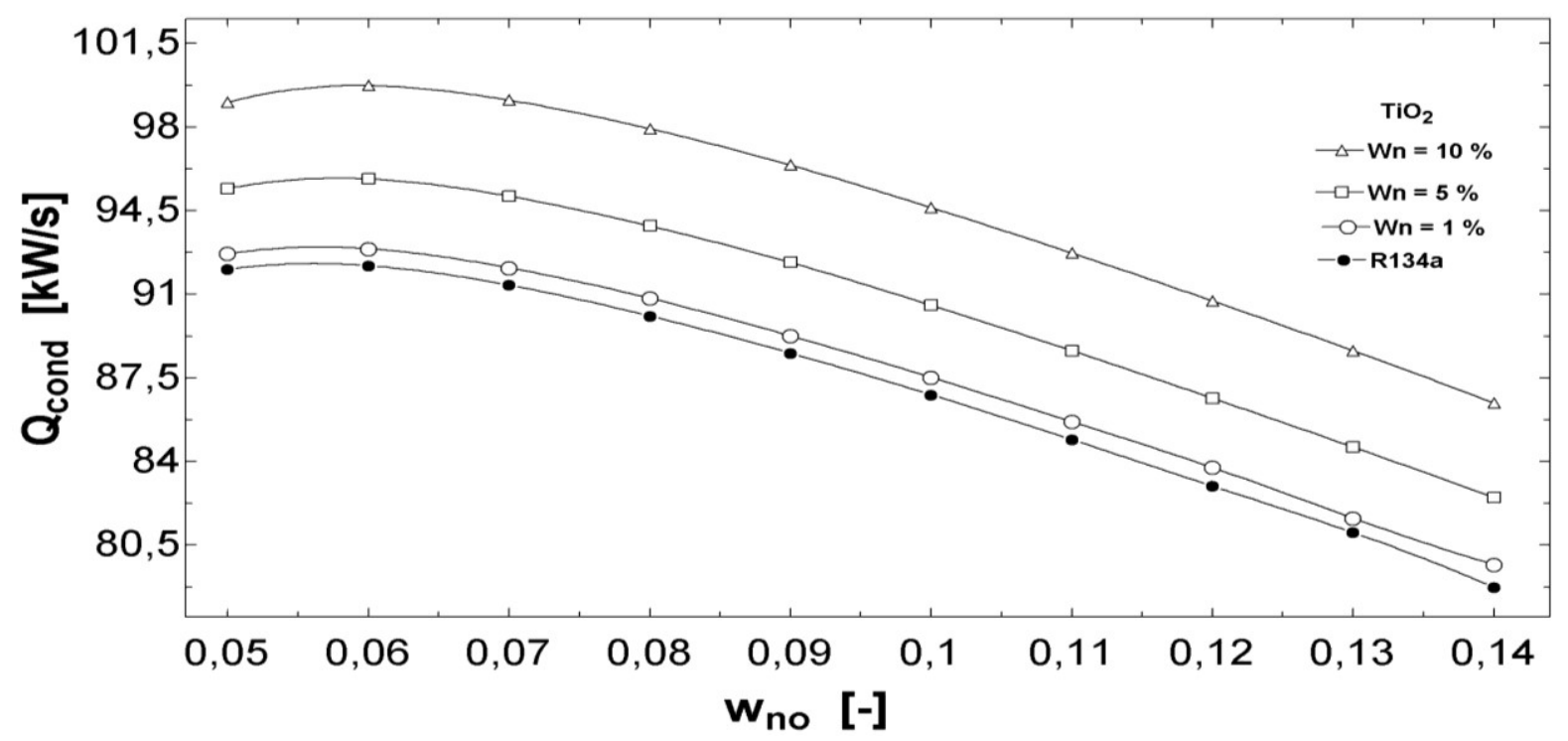

Figura 10 - Taxa de transferência de calor de condensação x Concentração do nano-óleo, para nanopartícula de dióxido de Titânio $\left(\mathrm{TiO}_{2}\right)$.

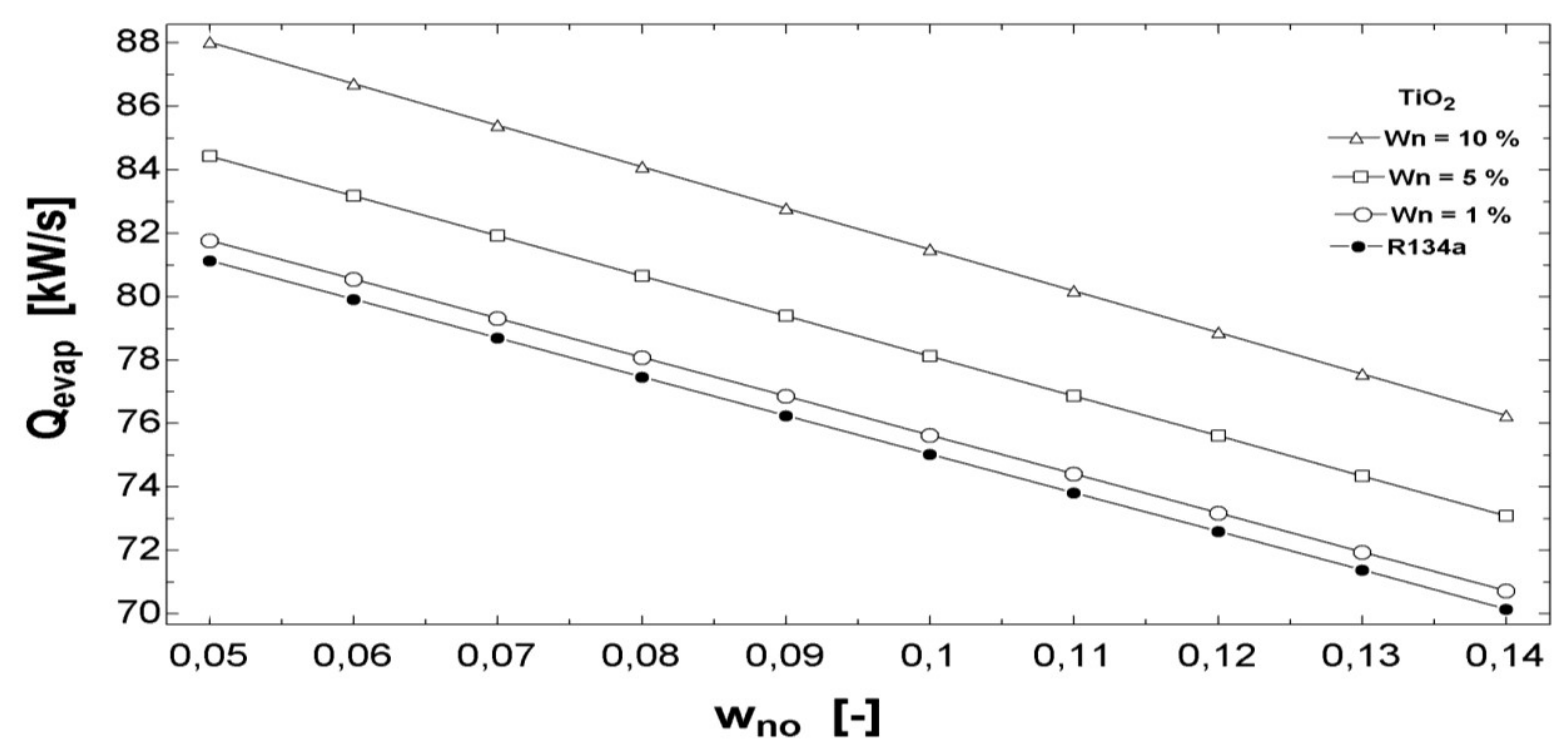

Figura 11 - Taxa de transferência de calor de evaporação x Concentração do nano-óleo, para nanopartícula de dióxido de Titânio $\left(\mathrm{TiO}_{2}\right)$. 


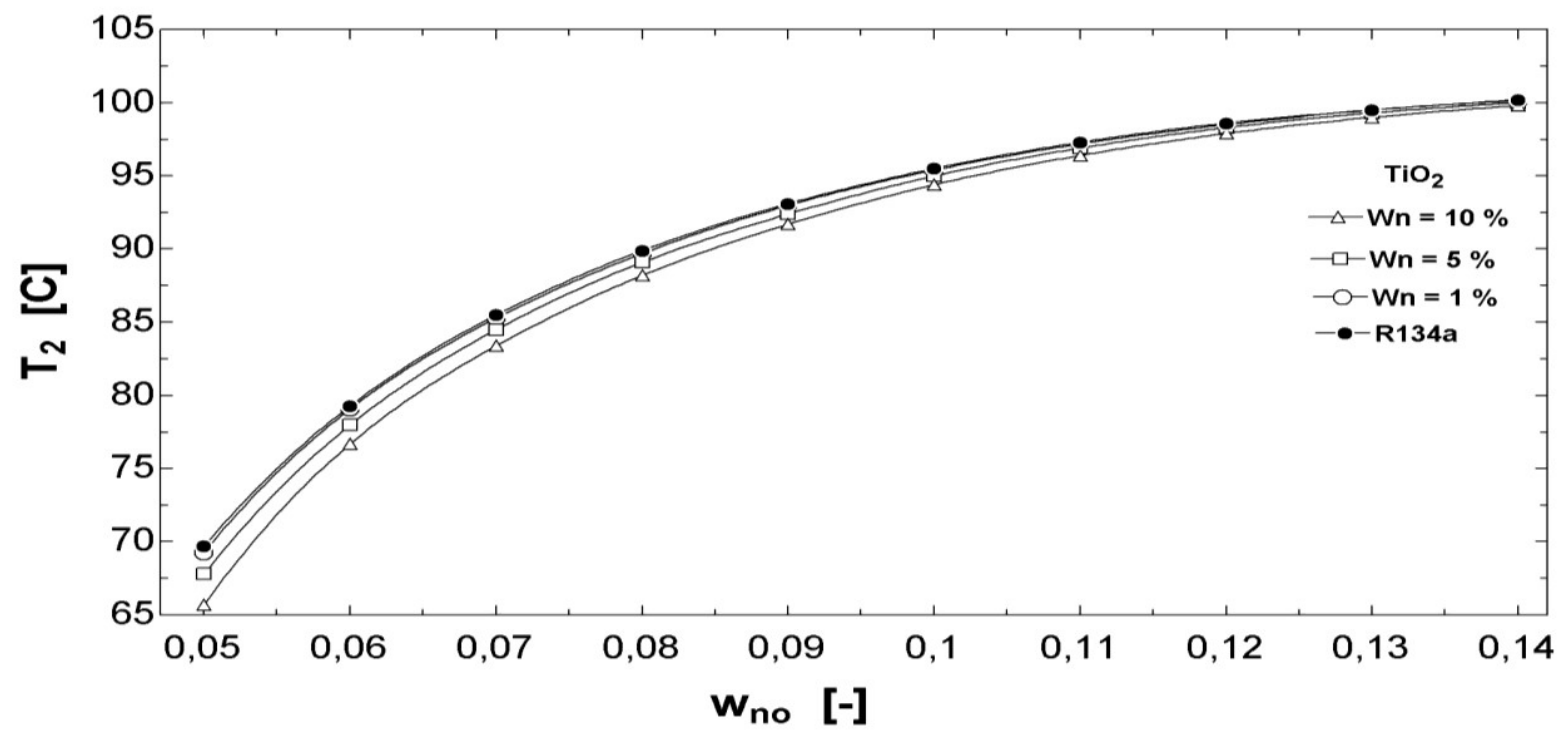

Figura 12 - Temperatura de descarga x Concentração do nano-óleo, para nanopartícula de dióxidode Titânio $\left(\mathrm{TiO}_{2}\right)$.

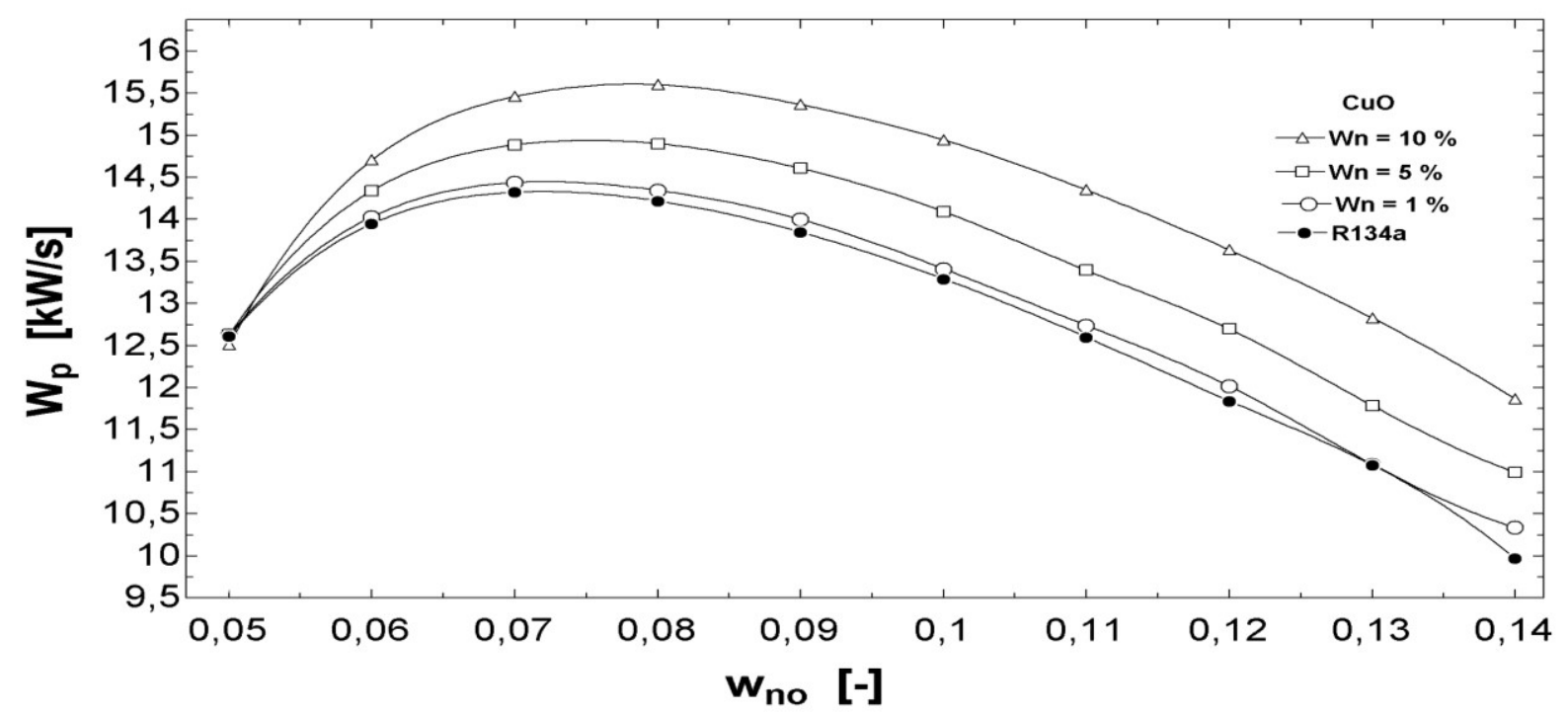

Figura 13 - Trabalho compressor x Concentração do nano-óleo, para nanopartícula de óxido de cobre (CuO) 


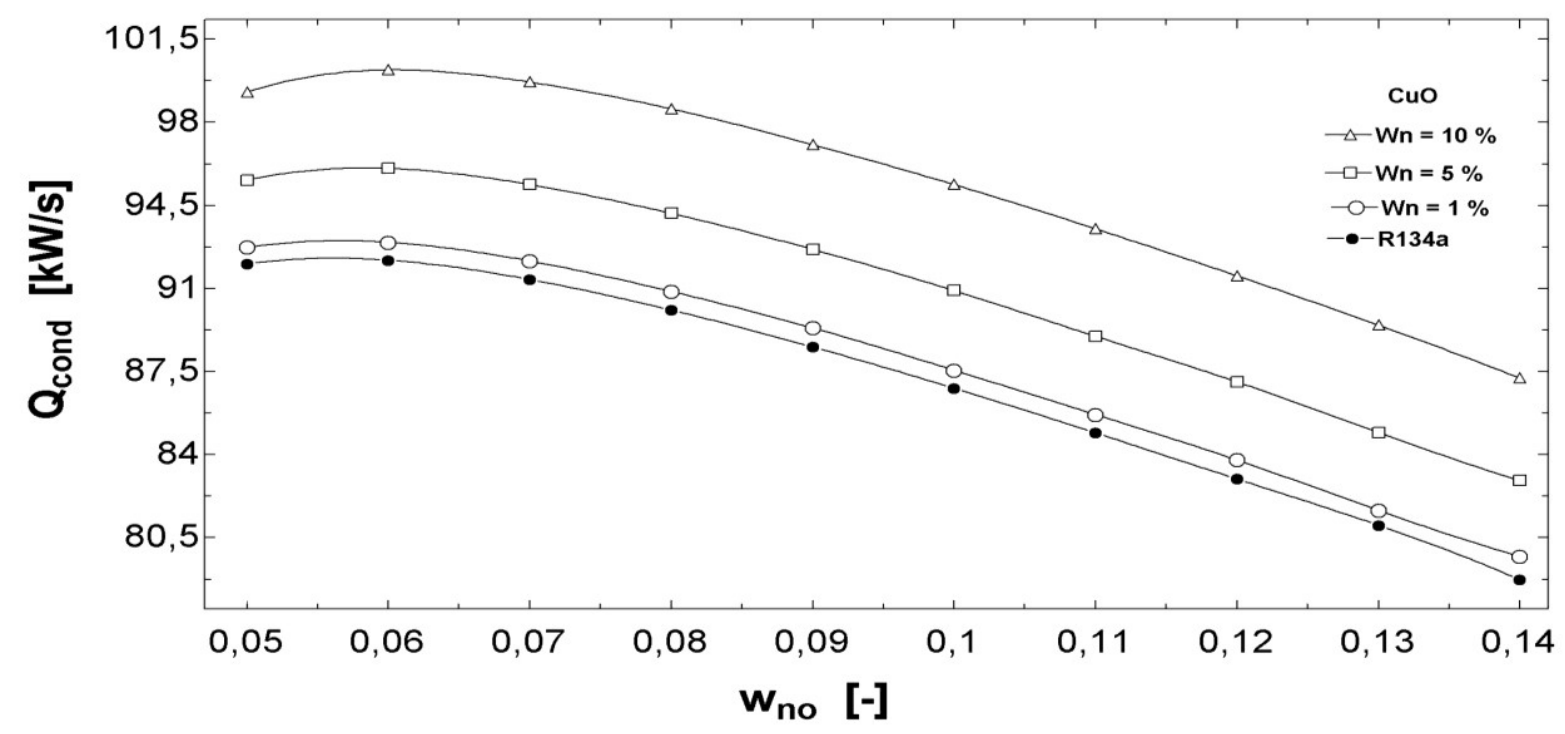

Figura 14 - Taxa de transferência de calor de condensação x Concentração do nano-óleo, para nanopartícula de óxido de cobre $(\mathrm{CuO})$

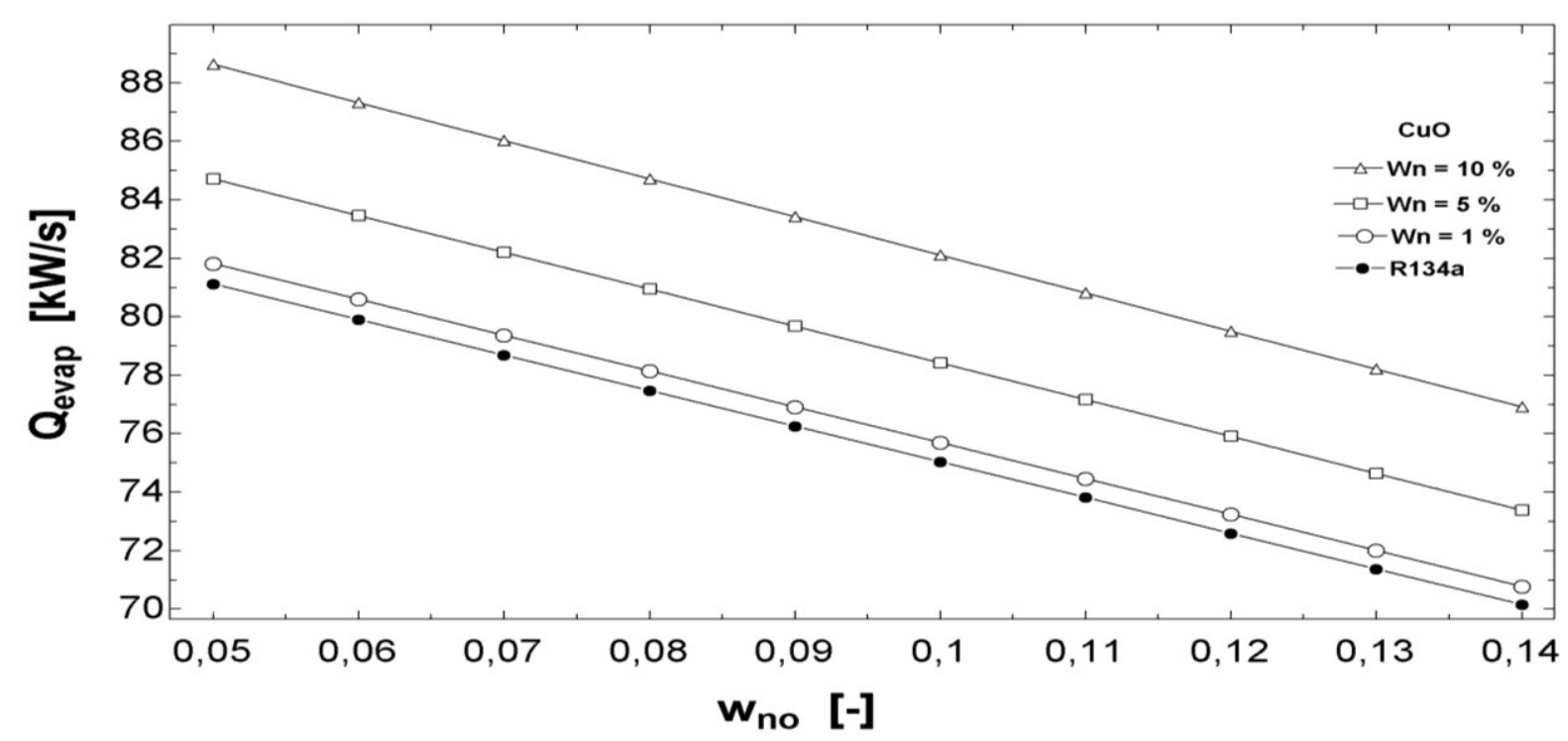

Figura 15 - Taxa de transferência de calor de evaporação x Concentração do nano-óleo, para nanopartícula de óxido de cobre $(\mathrm{CuO})$ 


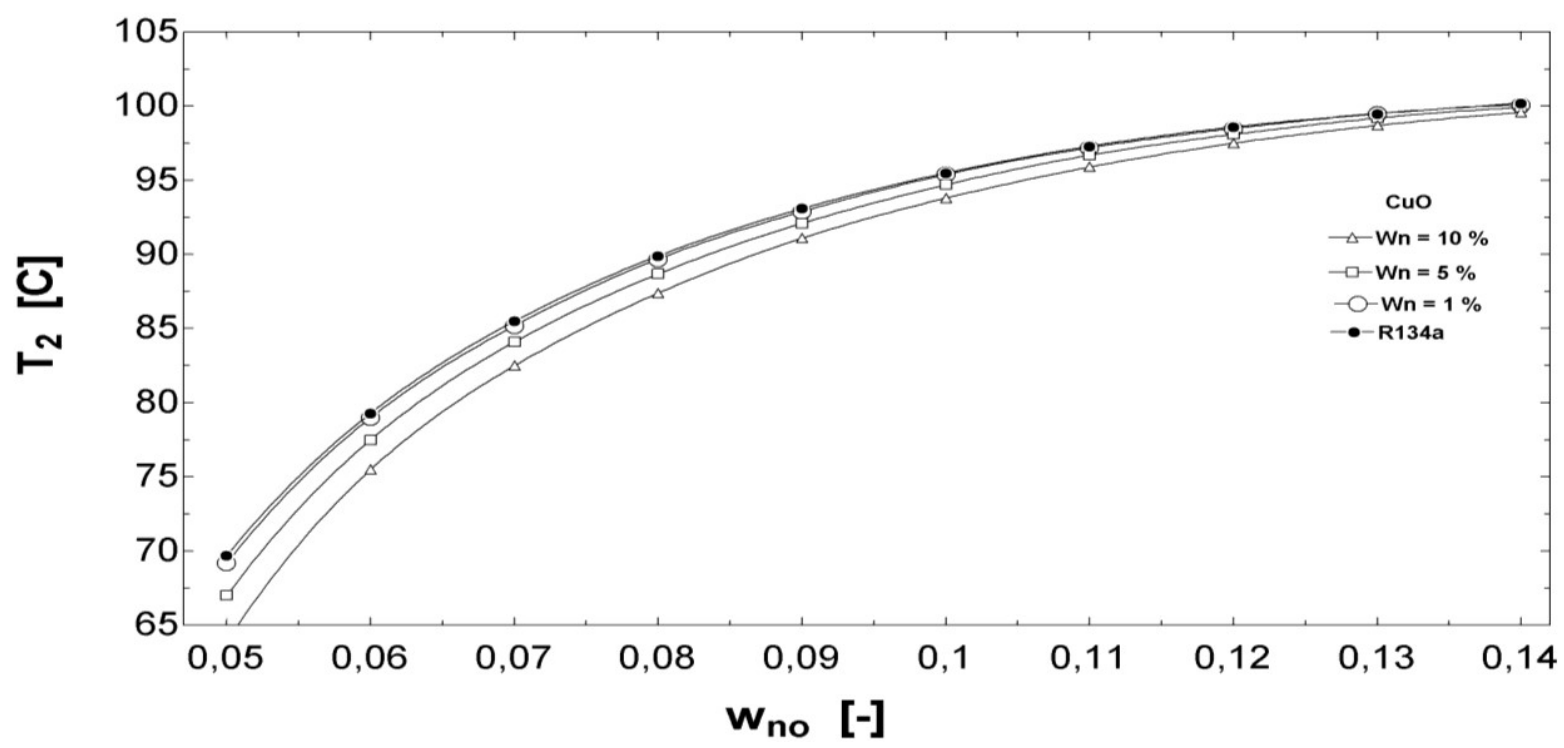

Figura 16 - Temperatura de descarga x Concentração do nano-óleo, para nanopartícula de óxido de cobre (CuO)

Analisaremos, a seguir, as três nanopartículas com a mesma concentração de $\omega_{\mathrm{n}}=1 \%$. Esta concentração é um pouco alta. Porém, para concentrações menores, não foi possível visualizar nenhuma tendência, ou do refrigerante puro R134a, para fazermos uma comparação entre eles. A concentração do nano-óleo utilizada foi a mesma das análises anteriores.

O gráfico da figura 17 mostra a variação do trabalho do compressor, $W_{p}$, para as diferentes nanopartículas, com a mesma concentração e do R134a puro. Observamos que, para as nanopartículas, os valores de $W_{p}$ são praticamente iguais, porém vemos um valor mais baixo de $W_{p}$ para o $\mathrm{TiO}_{2}$ quando aumentamos a concentração do nano-óleo. Agora, quando comparado com o R134a puro, vimos que o uso do refrigerante puro resulta na diminuição do valor do trabalho no compressor. 


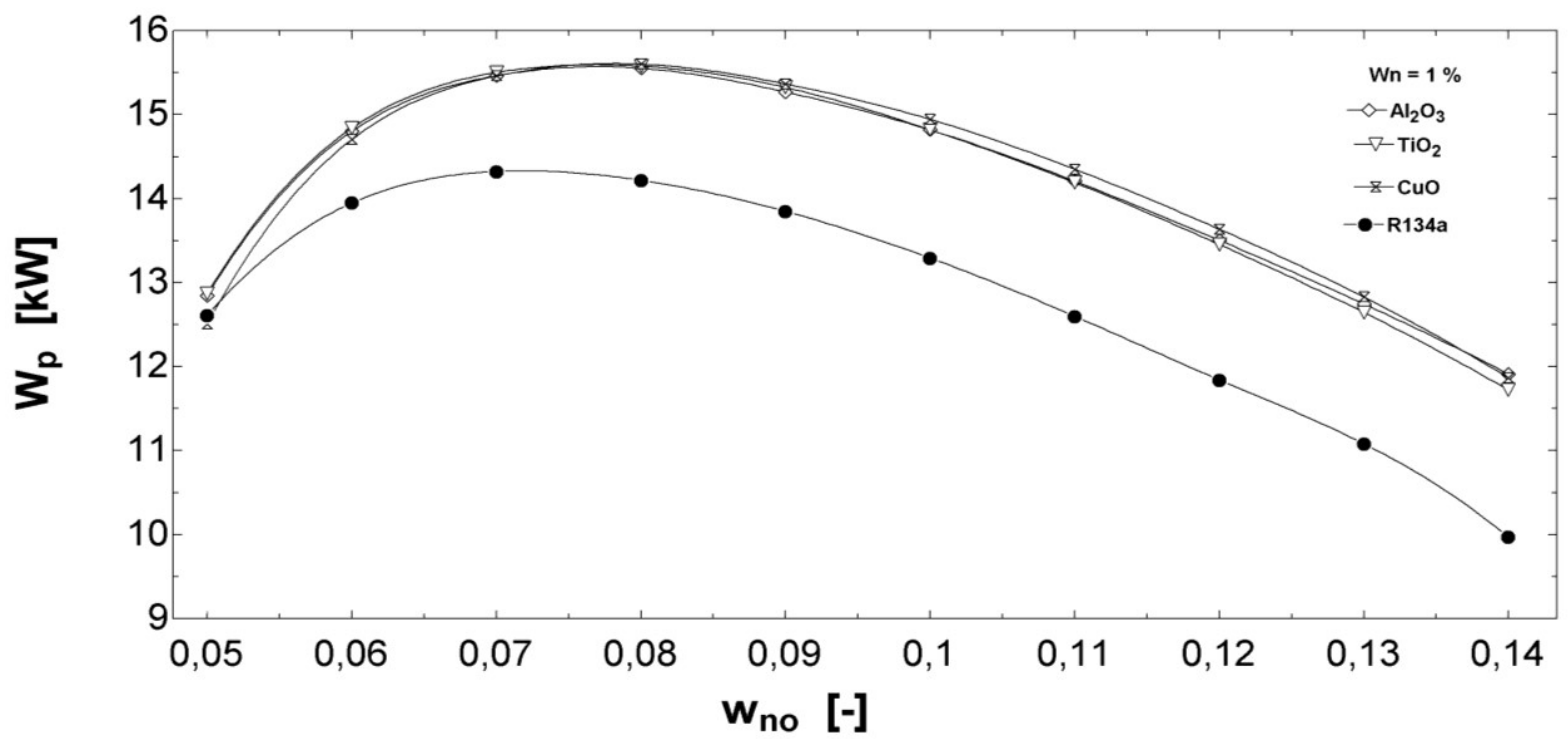

Figura 17 - Trabalho do compressor x Concentração do nano-óleo, para as três nanopartículas +R134a puro.

Na figura 18 fizemos a comparação entre as nanopartículas e o R134a puro, para a taxa de transferência de calor de condensação $\left(Q_{\text {cond }}\right)$. Observamos que o $\mathrm{CuO}$ quando comparado com $\mathrm{TiO}_{2}$ e $\mathrm{Al}_{2} \mathrm{O}_{3}$, está um pouco acima no gráfico. Já o refrigerante $\mathrm{R} 134 \mathrm{a}$ nota-se que há uma grande diferença entre ele e as nanoparticulas, o valor de $\left(Q_{\text {cond }}\right)$ é menor.

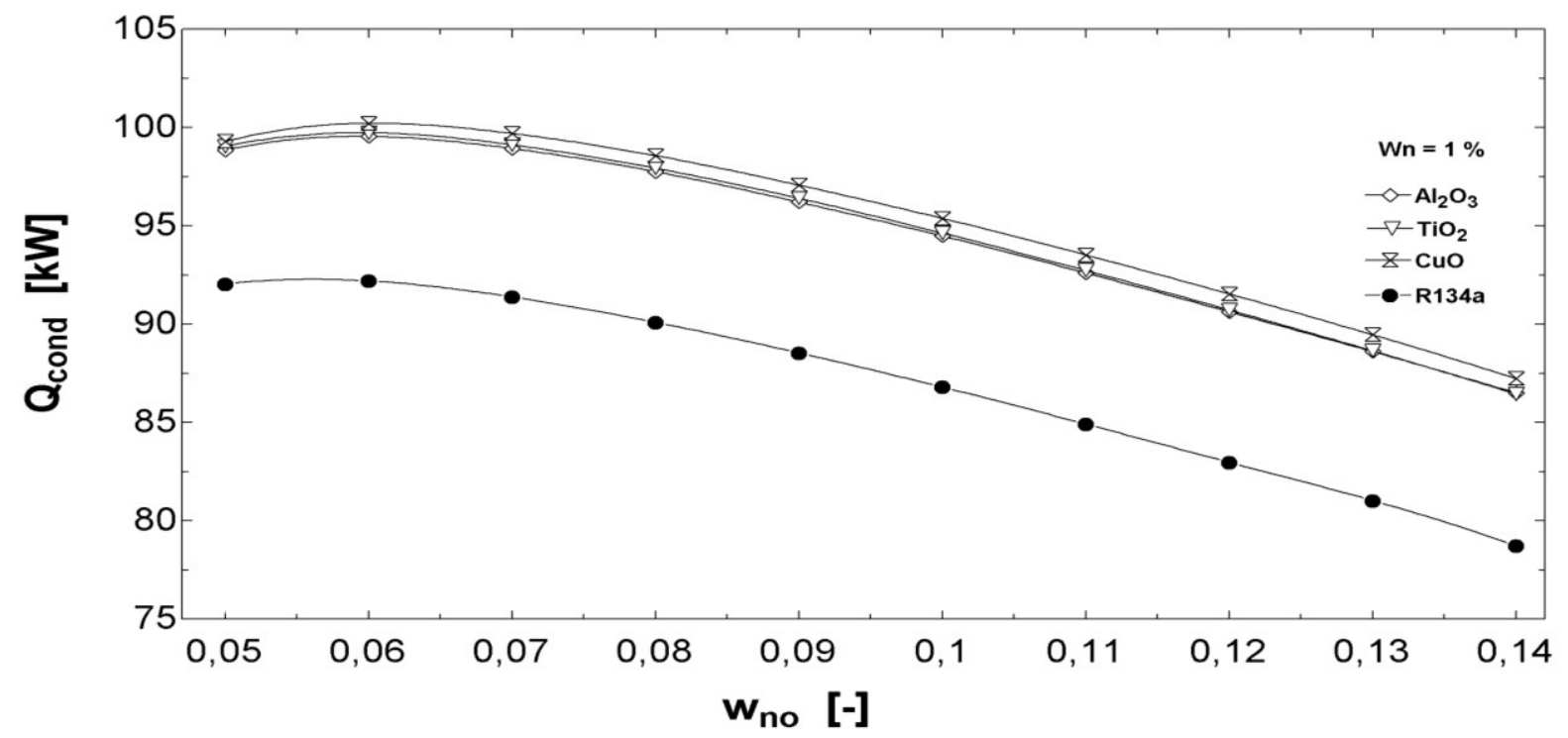

Figura 18 - Taxa de transferência de calor de condensação x Concentração do nano-óleo, para as três nanopartículas $+\mathrm{R} 134$ a puro. 
Para a taxa de transferência de calor de evaporação $\left(Q_{\text {evap }}\right)$ a figura 19 nos mostra que a nanopartícula de $\mathrm{CuO}$ também possui um valor de $\left(Q_{\text {evap }}\right)$ um pouco acima quando comparada com as outras nanopartículas, $\mathrm{TiO}_{2}$ e $\mathrm{Al}_{2} \mathrm{O}_{3}$. O refrigerante $\mathrm{R} 134 \mathrm{a}$ como esperado possui um valor bem abaixo em relação aos das nanopartículas.

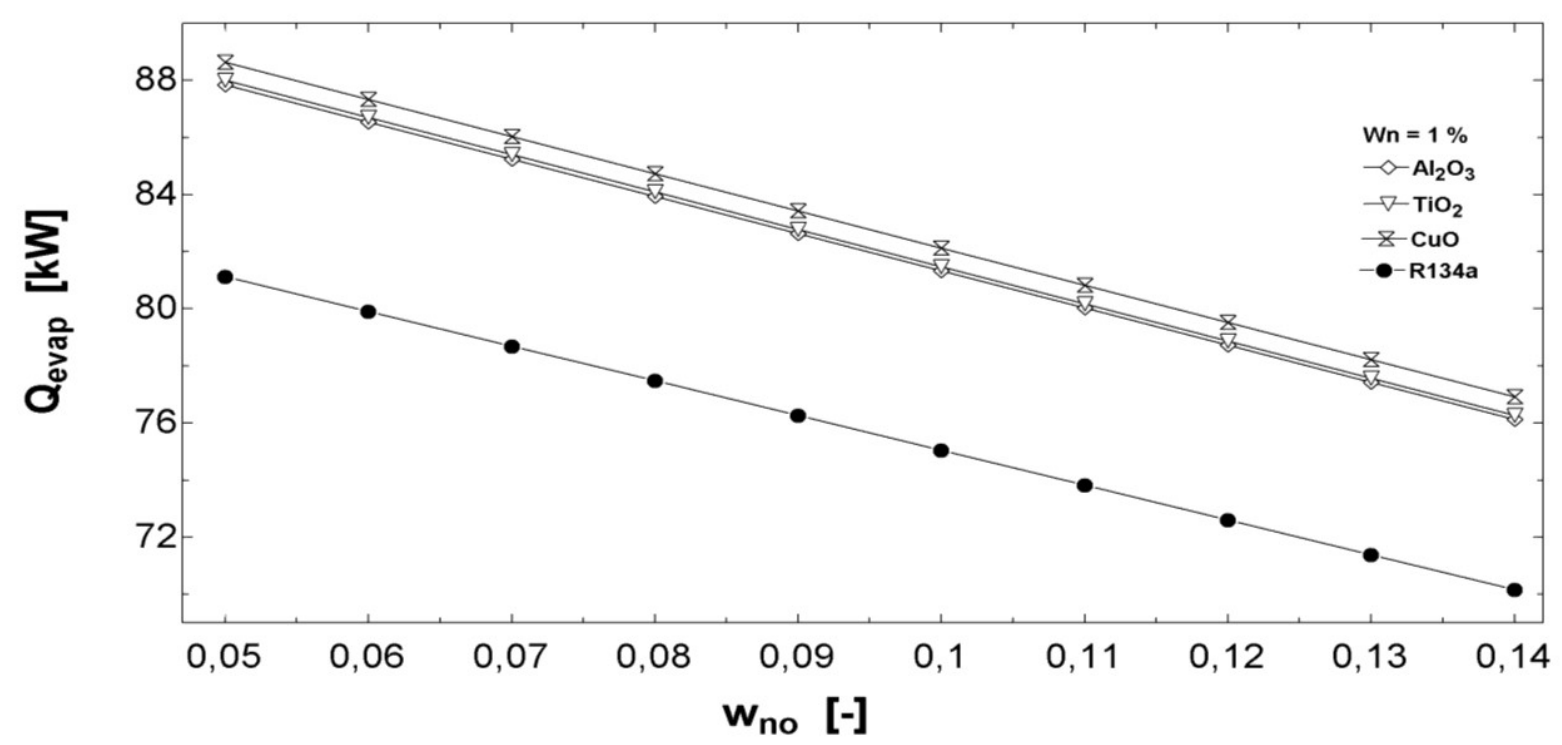

Figura 19 - Taxa de transferência de calor de evaporação x Concentração do nano-óleo, para as três nanopartículas $+\mathrm{R} 134$ a puro.

No gráfico da figura 20, podemos analisar a variação da temperatura de descarga $T_{2}$, para as diferentes nanopartículas. Do mesmo modo que analisamos uma faixa do gráfíco para a análise anterior da temperatura de descarga, faremos o mesmo para este gráfico, pois de acordo com os fabricantes de compressores os mesmos operam até no máximo uma temperatura de $90^{\circ} \mathrm{C}$. Com isso vimos que, entre as nanopartículas, não há uma que se destaque, sendo praticamente iguais os valores. Já para o R134a vemos uma temperatura de descarga maior quando comparado com as nanopartículas. 


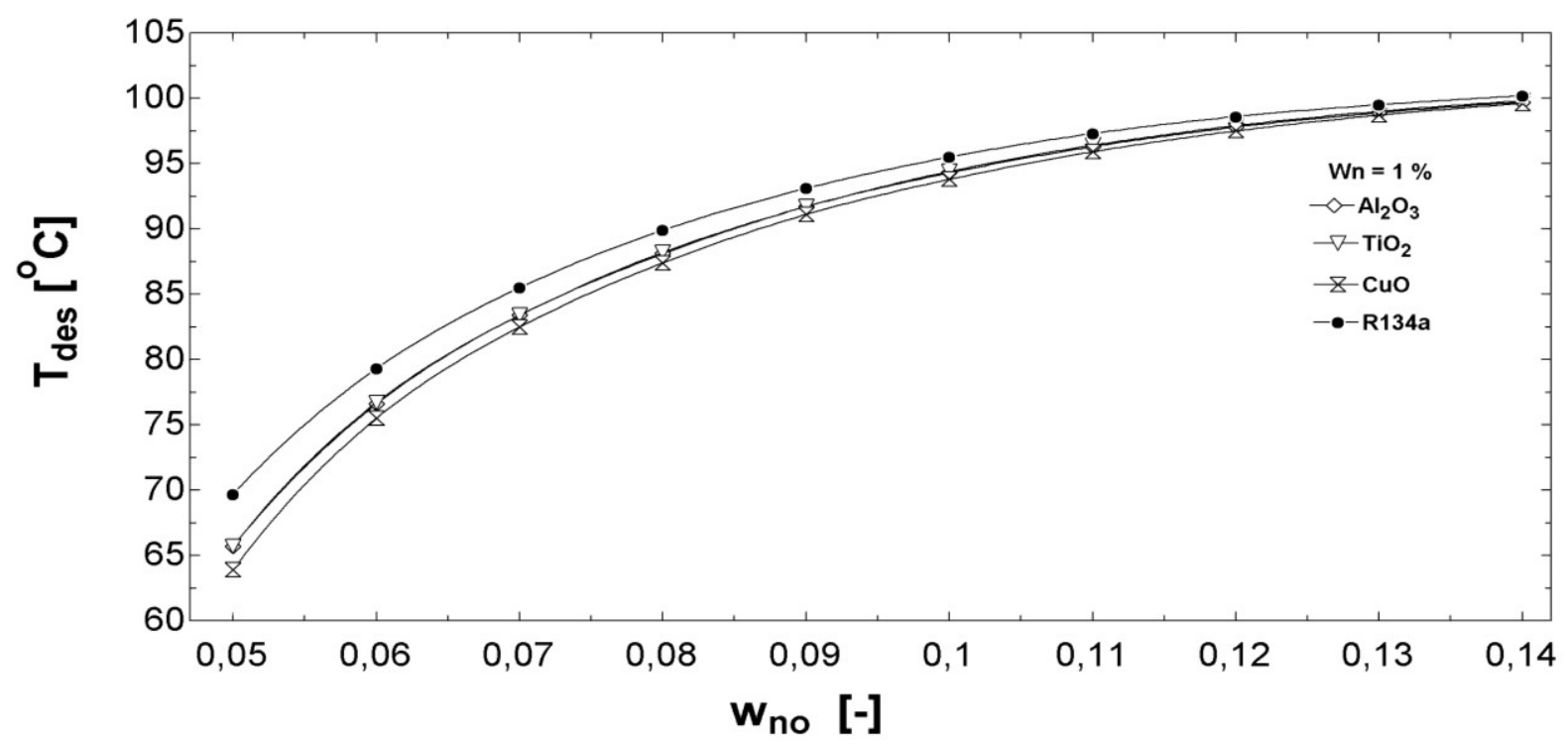

Figura 20 - Temperatura de descarga x Concentração do nano-óleo, para as três nanopartículas +R134a puro.

Por último faremos uma análise da vazão mássica $\dot{m}$ dos fluidos com as nanopartículas com concentração de $\omega_{n}=1 \%$, e do refrigerante R134a puro. Vemos, na figura 21, que o valor da vazão mássica do R134a é marginalmente menor quando comparado com as nanoparticulas, que praticamente possuem o mesmo valor de $\dot{m}$, com uma variação muito pequena entre si. Essa pequena variação pode ser explicada pelo valor da densidade das naopartículas, sendo a do $\mathrm{CuO}$ a maior delas. 


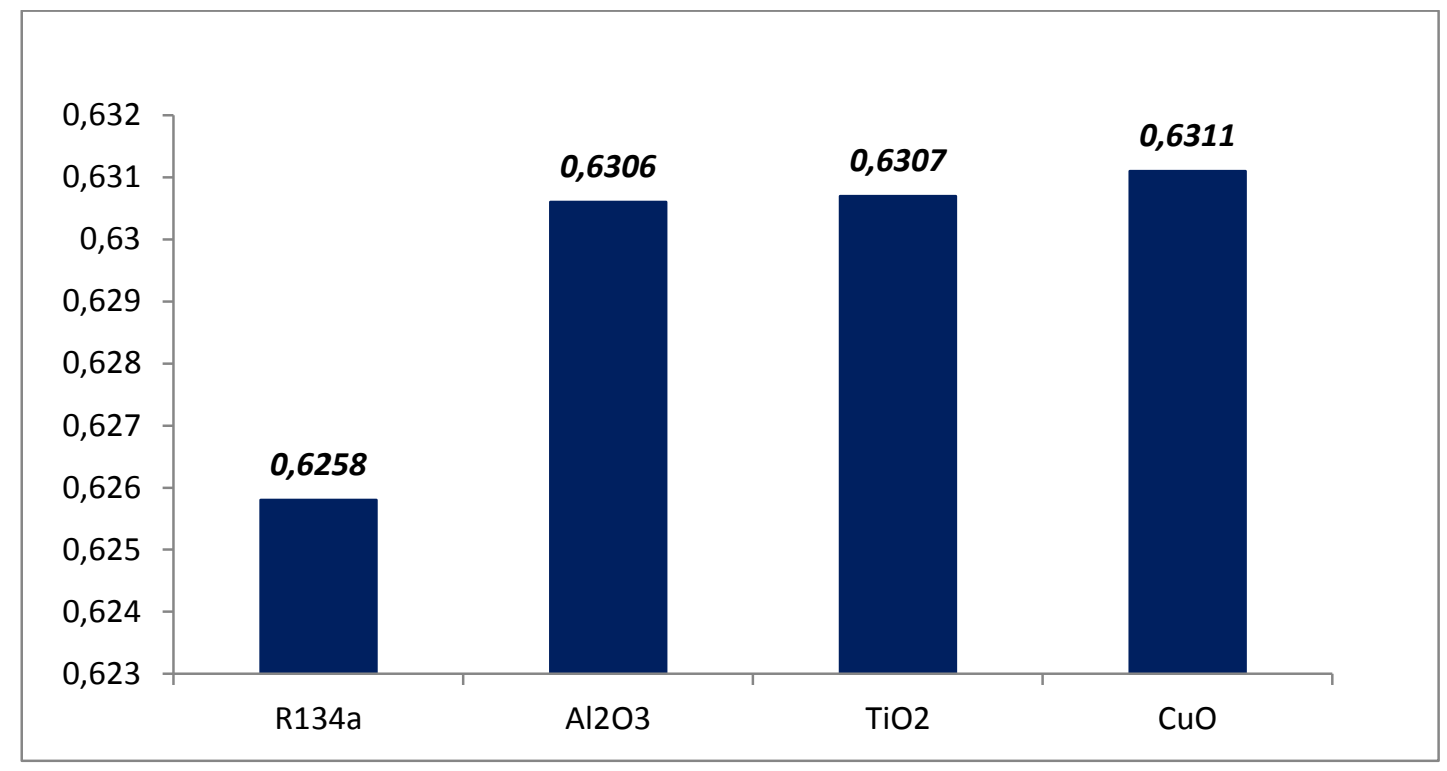

Figura 21 - Vazão mássica para: R134a; Al2O3; TiO2; CuO. 


\section{Conclusões}

Neste trabalho foi desenvolvido um modelo teórico para que a determinação das propriedades termofísicas de nanofluidos formados a partir de refrigerante e nanopartículas, com óleo lubrificante, em um ciclo de refrigeração por compressão a vapor. Feito isso pudemos avaliar os efeitos das nanopartículas, para diferentes concentrações de nanoparticulas e de óleo no ciclo.

O método desenvolvido, apesar de todo teórico mostrou-se bastante eficaz quando comparado com os dados experimentais presentes no artigo, pois o erro encontrado para as taxas de transferências de condensação e evaporação foram baixos. Já para o trabalho do compressor, o erro foi um pouco maior, na faixa de $12 \%$, isso pode ter ocorrido devido a algumas aproximações feitas, e de correlações usadas, como a própria equação de balanço que pode não ser a mais aconselhada para se usar com esse tipo de compressor (rotativo), sendo necessário o uso de uma nova correlação para minimizar o erro.

Ao analisarmos os nanolubrificantes com diferentes concentrações junto com o refrigerante puro, vimos que, para o trabalho no compressor, $W_{p}$, o ideal seria a utilização apenas do R134a puro, pois o mesmo apresentou um valor de $W_{p}$ baixo quando comparado com as nanopartículas, ou seja, utilizando o refrigerante temos um gasto menor de energia para fazer o compressor desempenhar a mesma função.

Já para as taxas de troca de calor, do condensador $\left(Q_{\text {cond }}\right)$ e do evaporador $\left(Q_{\text {evap }}\right)$, as tendências foram outras, as nanopartículas foram mais eficazes do que o refrigerante puro. Com o aumento das concentrações das nanopartículas obtivemos um aumento na taxa da troca de calor. 
Para a temperatura de descarga vimos que, quanto maior a concentração de nanopartícula, mais baixa é a temperatura de descarga. Com isso o trabalho no compressor $\left(W_{p}\right)$ se torna maior, como vimos.

Quando analisamos o estudo feito para as nanoparticulas com a mesma concentração (1\%) juntamente com o refrigerante R134a, vimos que, para o trabalho do compressor $W_{p}$, a escolha melhor para ser feita seria a da nanopartícula de dióxido de titânio, $\mathrm{TiO}_{2}$, pois foi a que apresentou um valor um pouco mais baixo do trabalho do compressor, dentre as nanopartículas comparadas.

Já para a análise da taxa de troca de calor de evaporação e de condensação, a nanopartícula que se apresentou um pouco mais eficaz foi a de óxido de cobre, $\mathrm{CuO}$, onde foi visto um aumento de $Q_{\text {cond }}$ e $Q_{\text {evap }}$, tornando assim a troca de calor com o ambiente mais eficiente.

Vimos que duas nanopartículas se destacaram nesse projeto, sendo elas a de dióxido de titânio, $\mathrm{TiO}_{2}$ e óxido de cobre, $\mathrm{CuO}$. Acreditamos que a escolha ideal seria a do $\mathrm{TiO}_{2}$, pois é a nanoparticula que faz com que o compressor gaste menos energia na hora de gerar o trabalho.

Calculamos também algumas propriedades termofísicas que não foram utilizadas no presente projeto, como por exemplo, a condutividade térmica. Que poderá ser utilizada e estudada nos próximos trabalhos de grupo de pesquisa. 


\section{Referências Bibliográficas}

Baustian, J.J., Pate, M.B. and Bergles, A.E., 1988, Measuring the concentration of a flowing oilrefrigerant mixture: instrument test facility and initial results, ASHRAE Transactions, Vol. 94, No. 1, pp. 167-177.

Brinkman, H.C., 1952, The viscosity of concentrated suspensions and solution, The Journal of Chemical Physics, Vol. 20, pp. 571-581.

Chandrasekar, M., Suresh, S. and Bose, A. C., 2010, Experimental investigations and theoretical determination of thermal conductivity and viscosity of A12O3/water nanofluid, Experimental Thermal and Fluid Science, vol. 34, pp 210-216.

Conde, M. R., 1996, Estimation of thermophysical properties of lubrificating oils and their solutions with refrigerants: an appraisal of existing methods, Applied Thermal Engineering, vol. 16, pp. $51-61$.

Duangthongsuk, W. and Wongwises, S., 2009, Measurement of temperature-dependent thermal conductivity and viscosity of $\mathrm{TiO}_{2}$-water nanofluids, Experimental Thermal and Fluid Science. 33, pp. 706-714.

Guzman, Andrade, 1930, Nature, pp. 125-309. 
Hamilton, R. L. and Crosser, O. K., 1962, Thermal conductivity of heterogeneous twocomponent systems, Industrial and Engineering Chemistry Fundamentals, vol. 1, pp. 187-191.

Jensen, M. K. and Jackman, D. L., 1984, prediction of nucleate pool boiling heat transfer coefficients of refrigerant-oil mixtures, Journal of heat Transfer, vol. 106, pp. 184-190.

Junod, A., Eckert, D., Triscone, G., Müller, J. and Reichardt, W., 1989, A study of the magnetic transitions in $\mathrm{CuO}$ : specific heat $(1-300 \mathrm{~K})$, magnetic susceptibility and phonon density of states, J. Phys, vol. 1, pp. 8021-8034.

Kedzierski, M. A., 2002, viscosity and density of $\mathrm{CuO}$ nanolubrificant, International Journal of Refrigeration vol. 35, pp. 1997-2002.

Kedzierskii, M. A. and Kaul, M. P., 1993, horizontal nucleate flow boiling heat transfer coefficient measurements and visual observations for R12, R134a/ester lubrificant mixtures, Proceedings of the $6^{\text {th }}$ International Symposium on Transport Phenomena in Thermal Engineering, vol. 1, pp. 111-116.

Kwak, K. and Kim, C., 2005, Viscosity and thermal conductivity of copper oxide nanofluid dispersed in ethylene glycol, Korea-Australia Rheology Journal, vol. 17, pp. 35-40.

Liley, P. E. and Gambill W. R., 1973, Physical and chemical data Chemical Engineering Handbook $5^{\text {th }}$ ed., New York: Mc Graw-Hill. 
Mahbubul, I. M., Kamyar, A., Saidur, R. and Amalina, M. A., 2013, Migration Properties of $\mathrm{TiO}_{2}$ Nanoparticles during the Pool Boiling of Nanorefrigerants, Ind. Eng. Chem. Res., vol. 52, pp. 6032-6038.

Mermond, Y., Feidt, M. and Marvillet, C., 1999, Propriétés thermodynamiques et physiques des mélanges de fluids frigorigènes et d'huiles, International Journal of Refrigeration vol. 22, pp. $569-579$

Pabst, W. and Gregorová, E., 2007, Effective thermal and thermoelastic properties of alumina, zirconia and alumina - zirconia composite ceramics, Nova Science Publishers, New York, pp. $77-137$

Saeedian, M., Shafiei, M. M., Shojaee, E. and Mohammadizadeh, M. R., 2013, Specific Heat Capacity of $\mathrm{TiO}_{2}$ Nanoparticles, University of Tehran, Iran, Departement of Physics, Brock University, Canada.

Vasconcelos, A. A., Parise, J. A. R., Sotomayor, P. O., Simulação de um compressor alternativo com uso de nanofluido como elemento lubrificante, (2014).

Wang, L., Tan, Z., Meng, S., Liang, D. and Li, G., 2001, Enhancement of molar heat capacity of nanostructured $\mathrm{Al}_{2} \mathrm{O}_{3}$, Journal of Nanoparticle Research 3, pp. 483-487.

Wang, X. Q. and Mujumdar, A. S., 2007, Heat transfer characteristics of nanofluids: a review, International Journal of Thermal Sciences, vol. 46, pp. 1-19. 